\title{
Mammalian target of rapamycin Hitting the bull's-eye for neurological disorders
}

\author{
Zhao Zhong Chong, Yan Chen Shang, Lijie Zhang, Shaohui Wang and Kenneth Maiese*
}

Department of Neurology and Neurosciences; Cancer Center; University of Medicine and Dentistry - New Jersey Medical School; Newark, NJ USA

\begin{abstract}
Key words: aging, Alzheimer disease, apoptosis, autophagy, diabetes, epilepsy, erythropoietin, fragile X syndrome, Huntington
\end{abstract} disease, immune system, ischemia, mTOR, neurodegeneration, oxidative stress, Parkinson disease, trauma, tuberous sclerosis

The mammalian target of rapamycin (mTOR) and its associated cell signaling pathways have garnered significant attention for their roles in cell biology and oncology. Interestingly, the explosion of information in this field has linked mTOR to neurological diseases with promising initial studies. mTOR, a $289 \mathrm{kDa}$ serine/threonine protein kinase, plays an important role in cell growth and proliferation and is activated through phosphorylation in response to growth factors, mitogens and hormones. Growth factors, amino acids, cellular nutrients and oxygen deficiency can downregulate mTOR activity. The function of mTOR signaling is mediated primarily through two mTOR complexes: mTORC1 and mTORC2. mTORC1 initiates cap-dependent protein translation, a rate-limiting step of protein synthesis, through the phosphorylation of the targets eukaryotic initiation factor 4E-binding protein 1 (4EBP1) and $\mathrm{p} 70$ ribosomal $\mathrm{S} 6$ kinase (p70S6K). In contrast, mTORC2 regulates development of the cytoskeleton and also controls cell survival. Although closely tied to tumorigenesis, mTOR and the downstream signaling pathways are significantly involved in the central nervous system (CNS) with synaptic plasticity, memory retention, neuroendocrine regulation associated with food intake and puberty and modulation of neuronal repair following injury. The signaling pathways of mTOR also are believed to be a significant component in a number of neurological diseases, such as Alzheimer disease, Parkinson disease and Huntington disease, tuberous sclerosis, neurofibromatosis, fragile $X$ syndrome, epilepsy, traumatic brain injury and ischemic stroke. Here we describe the role of mTOR in the CNS and illustrate the potential for new strategies directed against neurological disorders.

\section{Introduction}

Mammalian target of rapamycin (mTOR) is a serine/threonine protein kinase and has been known to play its role in cell growth and proliferation. mTOR is activated by phosphorylation in response to growth factors, mitogens and hormones. ${ }^{1-4}$ Rapamycin is a macrolide antibiotic from Streptomyces hygroscopicus that specifically inhibit the activity of mTOR. To foster its inhibitory effect on mTOR, rapamycin binds to immunophilin

*Correspondence to: Kenneth Maiese; Email: maieseke@umdnj.edu Submitted: 10/19/10; Accepted: 12/28/10; Accepted: 01/07/11

DOI: 10.4161/oxim.3.6.14787
FK-506-bidining protein 12 (FKBP12) to attach to mTOR, which prevents mTOR from phosphorylation. ${ }^{5}$ The function and regulatory pathway of mTOR have been extensively investigated and is gaining more broad attention in cancer research, development, metabolism and the central nervous system (CNS) diseases.

The mTOR protein is a $289 \mathrm{kDa}$ kinase that contains multiple protein domains. The carboxy-terminal acid terminal has a conserved sequence with homology to the catalytic domain of phosphoinositide-3-kinase (PI 3-K) family. ${ }^{6}$ The domain contains phosphorylation sites, such as threonine 2446, serine 2448 and serine 2481, which function to regulate mTOR activity. The phosphorylation of serine 2481 is an autocatalytic target of mTOR. ${ }^{7.8}$ The residue serine 2448 is the target of Akt (protein kinase B), another serine/threonine kinase and p70 ribosomal S6 kinase (p70S6K), while threonine 2446 is phosphorylated by AMP activated protein kinase (AMPK) and p70S6K.9.11 The C-terminal also contains FKBP12-rapamycin-associated protein (FRAP), ataxia-telengiectasia (ATM) and transactivtion/ transformation domain-associated protein domain (FAT). The FKBP12-rapamycin binding domain (FRB) is adjacent to the FAT domain and is the site of interaction between mTOR and FKBP protein bound to rapamycin. ${ }^{12}$ The $\mathrm{N}$-terminal of mTOR contains a tandemly repeated HEAT (Huntingtin, Elongation factor 3, A subunit of Protein phosphatase-2A and TOR1) motif, which provide protein interaction between mTOR complex with regulatory-associated protein with mTOR (Raptor) or rapamycin-insensitive companion of mTOR (Rictor) and has been associated with multimerization of mTOR. ${ }^{13}$

The mTOR exerts its functions mainly through two mTOR complexes: mTORC1 and mTORC2, ${ }^{14}$ in which mTOR associates with its regulatory proteins. In acute setting, rapamycin dominantly inhibits the activity of mTORC1. The mTORC2 is relatively resistant to rapamycin and prolonged treatment is required for rapamycin to inhibit the activity of mTORC2. ${ }^{15}$

The components of mTORC1 currently include (1) mTOR. mTOR is the catalytic subunit of the complex. (2) Raptor. Raptor is an essential component of the complex and functions to recruit mTOR substrate to the mTORC1 complex..$^{16,17}$ Raptor is a $150 \mathrm{kDa}$ mTOR binding protein that also binds to $4 \mathrm{EBP} 1$ and p70S6K. The binding of Raptor to mTOR is necessary for the mTOR-catalyzed phosphorylation of 4EBP1 in vitro, and it strongly enhances the mTOR kinase activity toward p70S6K. ${ }^{16}$ 
Table 1. The components of mTOR complex (mTORC) and their function

\begin{tabular}{|c|c|}
\hline Components & Function \\
\hline mTOR & Catalytic subunit of mTORC1 and mTORC2 \\
\hline Raptor & $\begin{array}{l}\text { An essential component of mTORC1, recruits mTOR } \\
\text { substrates to mTORC1and promotes the activity of } \\
\text { mTORC1 to } 4 \mathrm{EBP} 1 \text { and p70S6K }\end{array}$ \\
\hline Rictor & $\begin{array}{l}\text { Promotes the assembly and the activity of mTORC2, } \\
\text { stabilizes mSIN1 }\end{array}$ \\
\hline PRAS40 & $\begin{array}{l}\text { An mTORC1 binding partner and negatively regulates } \\
\text { the activity of mTORC1 by binding to mTORC1 }\end{array}$ \\
\hline mSIN1 & $\begin{array}{c}\text { A necessary component of mTORC2, promotes } \\
\text { the assembly and the activity of mTORC2 to } \\
\text { phosphorylate Akt at serine } 473\end{array}$ \\
\hline mSLT8 & $\begin{array}{l}\text { A necessary component for the stability of } \\
\text { Rictor-mTOR interaction and activity of mTORC2 }\end{array}$ \\
\hline Deptor & $\begin{array}{l}\text { Negatively regulates the activity of both mTORC1 and } \\
\qquad \text { mTORC2 }\end{array}$ \\
\hline Protor-1 & A Rictor binding subunit in mTORC2 \\
\hline
\end{tabular}

4EBP1, eukaryotic initiation factor 4E-binding protein 1; Deptor, DEP domain-containing mTOR-interacting protein; $\mathrm{mLST} 8$, mammalian lethal with $\mathrm{Sec} 13$ protein $8 ; \mathrm{mSIN1}$, mammalian stress-activated protein kinase interacting protein; mTOR, mammalian target of rapamycin; p70S6K, p70 ribosomal S6 kinase; PRAS40, proline-rich Akt substrate 40 kDa; Protor-1, protein observed with Rictor-1; Raptor, regulatory-associated protein of mTOR; Rictor, rapamycin-insensitive companion of mTOR.

(3) Proline rich Akt substrate $40 \mathrm{kDa}$ (PRAS40). PRAS40 is an mTORC1 binding partner that direct competitively inhibits the binding of mTORC1 substrate to Raptor..$^{18}$ Upon activation, mTOR can directly phosphorylate PRAS40 resulting in the dissociation of PRAS 40 with mTORC1. ${ }^{19}$ Phosphorylation of PRAS 40 on serine 183 and serine 221 by mTORC1, and threonine 246 by Akt leads to its dissociation from mTORC1, and its binding to 14-3-3 protein..$^{20}$ Phosphorylation of PRAS 40 on serine 221 and 183 but not serine-212 is sensitive to rapamycin treatment. ${ }^{19}$ (4) Mammalian lethal with Sec13 protein 8 (mLST8). The function in mTORC1 is not clear. (5) DEP-domain-containing mTORinteracting protein (Deptor). Deptor may negatively regulate the activity of mTORC1 and loss of Deptor activates mTORC1, ${ }^{21}$ (Table 1).

Similarly, mTORC2 consists of six different proteins (1) mTOR. (2) Rictor. Rictor is beneficial to the assembly and promotes the activity of mTORC2. ${ }^{22}$ Rictor is also essential for mTORC2 to activate Akt. ${ }^{23}$ The Rictor-mTOR complex directly phosphorylates $\mathrm{Akt} / \mathrm{PKB}$ on serine 473 in vitro and facilitates threonine 308 phosphorylation by phosphoinositidedependent kinase 1 (PDK1). ${ }^{23}$ (3) Mammalian stress-activated protein kinase interacting protein $(\mathrm{mSIN} 1)$. mSIN1 is necessary for the assembly of mTORC2 and for its capacity to phosphorylate Akt. ${ }^{24}$ Genetic ablation of $m \sin 1$ abolishes Akt-serine 473 phosphorylation and disrupts Rictor-mTOR interaction but maintains threonine 308 phosphorylation, suggesting that mSIN1-Rictor-mTOR complex in necessary for Akt serine 473 phosphorylation, which is required for TORC2 to support cell survival. ${ }^{25}$ (4) mLST8. mLST8 is necessary for the Rictor-mTOR interaction and for the stability and activity of mTORC2 complex. ${ }^{26}$ (5) Protein observed with Rictor-1 (Protor-1). Protor-1 is a Rictor-binding subunit of mTORC $2 .{ }^{27}$ Rictor and mSIN1 have been shown to stabilize each other to form the structural foundation of mTORC2 and is required for Akt phosphorylation. $^{25}$ (6) Deptor. Deptor also negatively regulates the activity of mTORC2. ${ }^{21}$

\section{Activation of mTOR Complex}

Growth factor and mTORC1. Growth factors activate G-protein coupled receptors and receptor tyrosine kinase and then stimulate mTORC1 by inhibiting tuberous sclerosis complex1 (TSC1)/ TSC2 through phosphoinositide 3 kinase (PI 3-K)-Akt and Rasextracellular signal-regulated kinase (ERK) mediated pathways (Fig. 1).

TSC1 (hamartin)/TSC2 (tuberin) complex is a negative regulator of mTORC1. TSC2 functions as a GTPase-activating protein (GAP), converting a small $G$ protein Ras homologue enriched in brain (Rheb) to the inactive GDP-bound form. ${ }^{28}$ The active GTP-bound Rheb can directly interact with Raptor and activate mTORC1 complex. Rheb also regulates the binding of 4EBP1 with mTORC1. ${ }^{29}$ The decreased activity of TSC1/TSC2 complex is mediated through the phosphorylation of TSC2 by Akt, ERK or p90 ribosomal S6 kinase 1 (RSK1). ${ }^{28,30-32}$ Rheb also can regulate mTOR through FKBP38, a member of FKBP family that is structurally related to FKBP12. FKBP38 is an endogenous inhibitor of mTOR and reduces the activity of mTOR through association with mTORC1. Rheb interacts directly with FKBP38 and prevents its association with mTOR in a guanosine 5 '-triphosphate (GTP)-dependent manner. ${ }^{33}$

Activation of Akt is dependent on PI 3-K..$^{34-39}$ The activation of the receptor tyrosine kinase (RTK) and the G protein-coupled receptor (CPCR) are required to activate PI 3-K. PI 3-K is composed of a catalytic p110 subunit and a regulatory p85 subunit. Growth factors or cytokines, can stimulate the recruitment of PI $3-\mathrm{K}$ to the plasma membrane. Following activation, PI 3-K phosphorylates membrane glycerophospholipid phosphatidylinositol 4,5-bisphosphate [PI $(4,5) \mathrm{P}_{2}$ ] resulting in the production of phosphatidylinositol 3,4,5-trisphosphate $\left(\mathrm{PIP}_{3}\right)$ and phosphatidylinositol 3,4-disphosphate ( $\mathrm{PIP}_{2}$ ). The critical step for activation of Akt is its transition from the cytosol to the plasma membrane by the binding of Akt to $\mathrm{PIP}_{2}$ and $\mathrm{PIP}_{3}$ through its $\mathrm{PH}$ domain. As a result of this sequence of events, Akt becomes available for phosphorylation by several upstream kinases. ${ }^{40,41}$

There may exist TSC1/TSC2 dependent and independent Akt signaling pathways to mTORC1. In the TSC1/TSC2 dependent pathway, activated Akt directly phosphorylates TSC2 on multiple sites resulting in the destabilization of TSC2 and disruption of its interaction with TSC1. ${ }^{28,42}$ The phosphorylation of TSC2 at the residues of serine 939 and 981 can result in its sequestration in the cytosol, where it is bound to the anchor protein 14-3-3, leading to the activation of Rheb and mTORC1..$^{30}$ In the TSC1/ TSC2 independent pathway involves the mTORC1 binding protein PRAS40. Activated Akt phosphorylates PRAS40 and dissociates its binding to Raptor of the $\mathrm{mTORC} 1$ complex and releases 


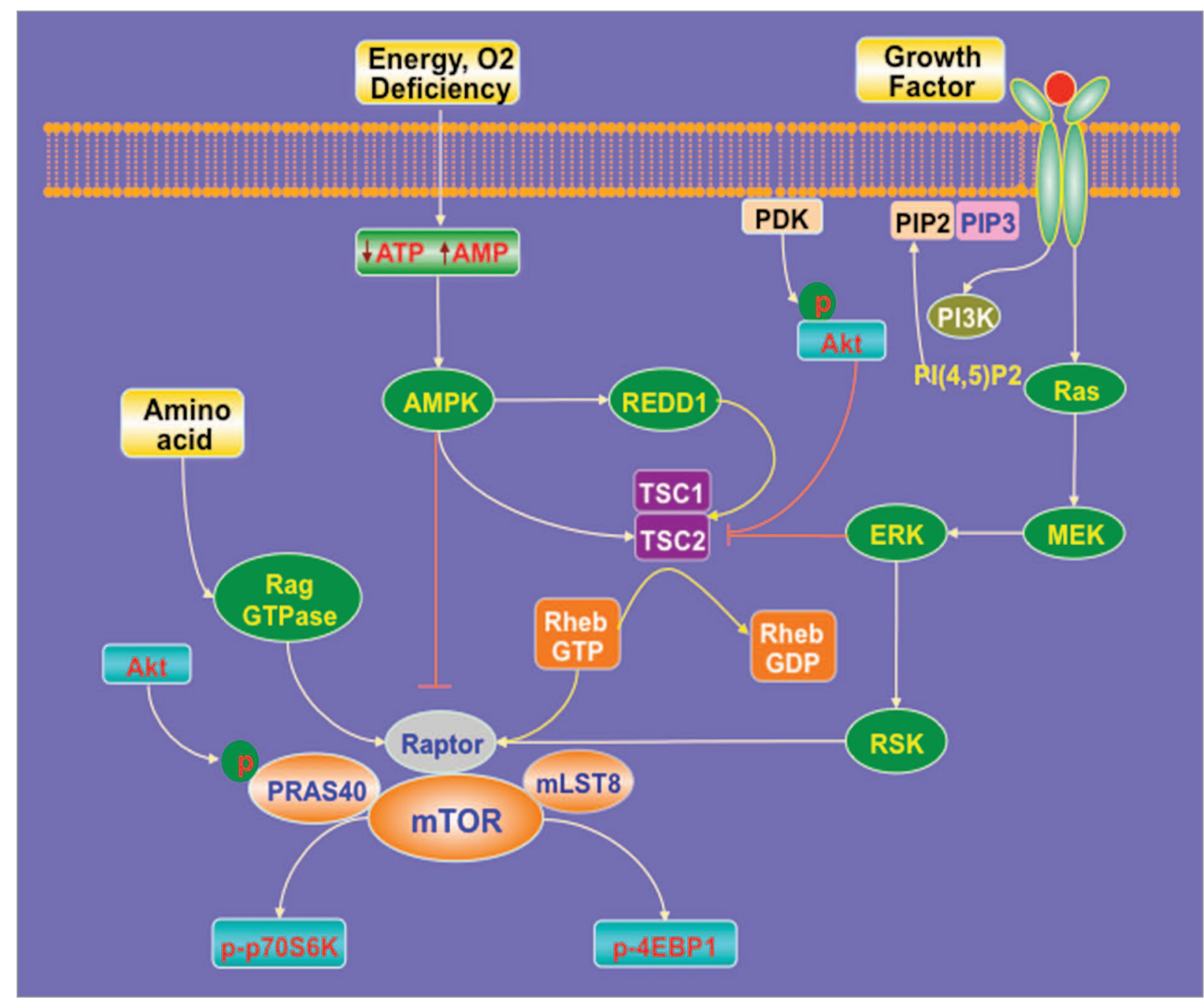

Figure 1. Activation of mammalian target of rapamycin complex 1 (mTORC1). Growth factors activate mTORC1 through both phosphoinositide 3 kinase (PI 3-K)-Akt and Ras-extracellular signal-regulated kinase (ERK) mediated pathways. Activation of Akt is dependent upon PI 3-K. Growth factors or cytokines, can stimulate the recruitment of PI 3-K to the plasma membrane. Following activation, PI 3-K phosphorylates membrane glycerophospholipid phosphatidylinositol-4,5-bisphosphate $\left[\mathrm{PI}(4,5) \mathrm{P}_{2}\right]$ resulting in the production of phosphatidylinositol-3,4,5-trisphosphate $\left(\mathrm{PIP}_{3}\right)$ and phosphatidylinositol-3,4-disphosphate $\left(\mathrm{PIP}_{2}\right)$. Akt is translocated from the cytosol to the plasma membrane through the binding to $\mathrm{PIP}_{2}$ and $\mathrm{PIP}_{3}$ through its $\mathrm{PH}$ domain. As a result of this sequence of events, Akt becomes available for phosphorylation by its upstream kinases, such as phosphoinositidedependent kinase 1 (PDK1). Activated Akt can phosphorylate tuberous sclerosis complex-2 (TSC2), resulting in the disruption of its interaction with TSC1, activation of Ras homologue enriched in brain (Rheb) and subsequent activation of mTORC1. Akt can also directly phosphorylate proline rich Akt substrate $40 \mathrm{kDa}$ (PRAS40) and reduce its binding to regulatory associated protein of mTOR (Raptor) and release its suppression of mTORC1. In the ERK mediated mTORC1 activating pathway, ERK is activated upon Ras induced activation of mitogen activated kinase/ERK kinase (MEK) and then phosphorylation of TSC2 ensues. ERK also can activate the ribosomal S6 kinase (RSK), which phosphorylates Raptor resulting in the activation of mTORC1. Oxygen deprivation or hypoxia reduces cellular ATP level and stimulates AMP activated protein kinase (AMPK) which may induce the expression of transcriptional regulation of DNA damage response 1 (REDD1), releasing TSC2 from the binding to protein 14-3-3 and inhibiting mTORC1 activity. Similarly, cellular energy deficiency also activates AMPK, which phosphorylates TSC2 promoting its GTPase activating protein activity and turning Rheb-GTP into Rheb-GDP and subsequent inhibits mTORC1 activity. AMPK induced phosphorylation of Raptor on serine 722 and 792 also results in the inhibition of mTORC1 activity. Amino acids can induce relocalization of mTORC1 and activate Rag GTPase, which binds to Raptor and activates mTORC1. Upon activation, mTORC1 phosphorylates its two major downstream targets p70 ribosome S6 kinase (p70S6K) and eukaryotic initiation factor 4E-binding protein 1 (4EBP1).

mTORC1 from the suppression by PRAS40, ${ }^{18,43-46}$ facilitating the activation of mTORC1.

In the insulin induced Akt-mTORC1 activated signaling pathway, a negative feedback loop has been found. Downstream of Akt activation is the mTORC1 activated signaling event, which reversely repress insulin PI 3-K-Akt axis. The underlying mechanism may involve the insulin receptor substrate 1 (IRS1). Following activation, mTORC1 phosphorylates and activates its downstream target p70S6K, which then phosphorylates and inhibits IRS1, the upstream of PI 3-K. ${ }^{47}$

In addition to PI 3-K/Akt signaling pathway, Ras-ERK signaling has also been associated with the activation of mTORC1 
in response to growth factors. In the ERK mediated mTORC1 activating pathway, ERK is activated upon Ras induced activation of mitogen activated kinase/ERK kinase (MEK) and then the phosphorylation of TSC2 ensues. ERK-dependent phosphorylation on serine 664 of TSC2 leads to TSC1-TSC2 dissociation and impairment of TSC2 ability to inhibit mTOR signaling, suggesting that the Ras/MAPK pathway upstream of the TSC complex and that ERK may modulate mTOR signaling pathway and contribute to disease progression through phosphorylation and inactivation of TSC2. ${ }^{31}$

The phosphorylation of Raptor also regulates the activity of mTORC1. Activation of the Ras-ERK pathway leads to high Raptor phosphorylation on RXRXXpS/T consensus motifs and RSK 1 and 2 are required for Raptor phosphorylation. Importantly, Raptor mutants lacking RSK-dependent phosphorylation sites markedly reduces mTOR phosphotransferase activity, suggesting that RSK-mediated phosphorylation of Raptor is important for mTORC1 activation through the Ras-ERK pathway. ${ }^{48}$ Rheb overexpression also increases phosphorylation on Raptor serine 863 as well as on the five other identified sites (serine 859, 855, 877, 696 and threonine 706). In addition, Raptor serine 863 phosphorylation functions as a master biochemical switch that modulates hierarchical raptor phosphorylation (phosphorylation on serine 863 is required for phosphorylation on serine 859 and serine 855). Moreover, Raptor defect leads to a reduced activity of mTORC1. ${ }^{49}$ Upon activation, mTOR also phosphorylates Raptor in vitro and in vivo, which is stimulated by insulin and inhibited by rapamycin. More importantly, the site-directed mutation of Raptor on serine 863 reduces mTORC1 activity. ${ }^{50}$ Consequently, manipulating the phosphorylation of Raptor mediates the activation of mTORC1.

Cellular energy deficiency and mTORC1 activation. The energy and nutrient level of the cells can also modulate the activity of mTORC1. The lowered cellular energy status downregulates the activity of mTORC1 $1^{11,52}$ through AMPK mediated cell signaling pathway. ${ }^{53}$ AMPK serves as a sensor for cellular energy status and can be activated by increased level of AMP or AMP/ ATP ratio. ${ }^{54}$ Upon activation, AMPK phosphorylates TSC2 at the residue of serine 1387 (human) or serine 1345 (rat), promoting its GAP activity to turn Rheb-GTP into Rheb-GDP and thereby inhibiting the activity of mTORC1.53 While in TSC2 null cells, activation of AMPK still partially inhibits mTORC1, suggesting that there exists an alternative pathway for AMPK signals to mTORC1. ${ }^{55}$ The mTORC1 component Raptor have been identified as a direct substrate of AMPK and demonstrate that AMPK directly phosphorylates Raptor at two conserved serine sites: serine 722 and serine 792 , resulting in the binding of Raptor to a cytoplasmic dock protein 14-3-3 and resulting in the inhibition of mTORC1. . $^{53,56}$

Upstream of AMPK is the LKB1, a tumor suppressor. LKB1 is a serine/threonine kinase and a major kinase that phosphorylates AMPK under the condition of cellular energy deficiency. ${ }^{54}$ LKB1 phosphorylates AMPK at threonine 172 resulting in AMPK activation followed by inhibition of mTORC1. ${ }^{57}$ Recently, the tumor suppressor $\mathrm{p} 53$ has been demonstrated to activate AMPK under oxidative and genotoxic stress. ${ }^{58}$ Two p 53 target genes, sestrin 1 and sestrin 2, have been identified to suppress mTORC1. verexpression of Sestrin1 and Sestrin 2 activates AMPK, which phosphorylates TSC2 and stimulates its GAP activity and thus inhibits the activity of mTORC1. ${ }^{58}$

Oxygen deprivation and mTORC1 activation. Hypoxia reduces ATP level and activates AMPK, which then downregulates the activity of mTORC1 through activating TSC1/2 complex. ${ }^{59}$ Hypoxia also induces the inhibition of mTORC1 through a mechanism that involves transcriptional regulation of DNA damage response 1 (REDD1). ${ }^{60-62}$ Hypoxia induced reduction in mTORC1 activity correlates with increased expression of the hypoxia-inducible REDD1 gene. Disruption of REDD1 abrogates the hypoxia-induced inhibition of mTOR. In contrast, REDD1 overexpression is sufficient to downregulate mTORC1 activity in a TSC1/TSC2-dependent manner ${ }^{60}$ Further study indicates that hypoxia and REDD1 suppress mTORC1 activity by releasing TSC2 from its inhibitory binding to protein 14-3-3 induced by growth factors. Endogenous REDD1 is required for hypoxia induced dissociation of endogenous TSC2/14-3-3 and subsequent inhibition of mTORC1. ${ }^{61}$ Interestingly, AMPK inhibition prior to hypoxia prevents REDD1 expression and thereby sustains mTOR activity in neck squamous cell carcinoma, ${ }^{63}$ suggesting that AMPK activation after hypoxia may be crucial in regulating REDD1 expression to control the mTOR activity. In addition, hypoxia induced expression of REDD1 may also be dependent on hypoxia inducible factor $1 \alpha$ (HIF-1 $\alpha)$ activation. ${ }^{64,65}$

Amino acid and mTORC1 activation. Amino acid level is also a strong stimulant that regulates the mTORC1 activity. Amino acids, especially leucine, an essential amino acid, are required for mTORC1 activation. Amino acid starvation results in rapid inhibition of mTORC1 signaling. ${ }^{66-72}$ Cellular uptake of L-glutamine and its subsequent rapid efflux followed by influx of essential amino acids has been proposed to be the rate-limiting step that activates mTOR. ${ }^{73}$ Interestingly, in $\mathrm{TSC}^{-/-}$cells, amino acid deprivation still impairs the mTORC1 signaling, suggesting that amino acid regulate the activity of $\mathrm{mTORC} 1$ through a mechanism that is independent of TSC1/TSC2 complex. ${ }^{74}$

The two human proton-assisted amino-acid transporters (PATs), PAT1 and PAT4, have been identified to be required for amino acid induced the activation of mTORC1 in starved HEK293 cells. PAT1 is highly concentrated in intracellular compartments in HEK-293 cells, including endosomes. ${ }^{75}$ Recent study has shown that the presence of amino acids relocate the dispersed cytoplasmic mTOR to endosomal compartments around which Rheb accumulates in HEK-293 cells. ${ }^{76}$ PATs could have a role in transmitting the amino-acid signal from the cortical cytoplasm to mTORC1. ${ }^{75}$

Recently, Rag proteins have been linked to amino acid sensing and the regulation of $\mathrm{mTORC} 1$ signaling. ${ }^{76-78}$ Rag proteins are a family of four related guanosine phosphatases (GTPases). The expression of a Rag mutant that is constitutively bound to GTP within cells results in the resistance of the mTORC1 pathway to amino acid deprivation and conversely, expression of a GDPbound Rag mutant prevents stimulation of mTORC1 by amino acids. $^{76}$ 
In mammalian cells, the RagA or RagB forms heterodimers with either RagC or RagD and the resulting heterodimers strongly bind to Raptor. The binding of Rag GTPases to Raptor, is necessary and sufficient to mediate amino acid signaling to mTORC1, and mediates the amino acid induced re-localization of mTORC1 within the endomembrane system of the cell. mTORC1 is generally distributed throughout the cytoplasm but with amino acid stimulation it is rapidly relocalized to the perinuclear region that contains the mTORC1 activator Rheb. ${ }^{76}$ Recent study indicates that amino acids induce translocation of mTORC1 to lysosomal membranes, where the Rag proteins reside. The complex Regulator encoded by the MAPKSP1, ROBLD3 and c11orf59 genes interacts with the Rag GTPases, recruits them to lysosomes leads to mTORC1 activation. Thus, Rag-Ragulator-mediated translocation of mTORC1 to lysosomal membranes is the key event in amino acid signaling to mTORC1. ${ }^{78}$

Activation of mTORC2. Compared to mTORC1, the signaling pathway to activate mTORC2 is far from elucidation. The TSC1/2 complex has been associated with regulation of mTORC2 activity, however, in contrast to inhibiting the activity of mTORC1, TSC1/2 complex seems to promote the activity of mTORC2. ${ }^{79}$ Lack of functional TSC1/TSC2 complex in cells results in the loss of the mTORC2 kinase activity in vitro. The study indicates that TSC1/2 complex can physically associate with mTORC2 to enhance the activity of mTORC2 using a mechanism that is independent of its GAP activity toward Rheb. ${ }^{79}$ Further study indicates that TSC $1 / 2$ complex can directly stimulate the in vitro kinase activity of mTORC2 may through the interaction between the N-terminal region of TSC2 and the C-terminal region of the mTORC2 essential component Rictor. ${ }^{80}$

To regulate the activity of $\mathrm{mTORC} 2$, there may exist interaction between mTORC1 and mTORC2. The essential mTORC2 component Rictor is phosphorylated on the residue of threonine 1135 by growth factors that is sensitive to rapamycin and is downstream of mTORC1. The activated p70S6K1, the downstream activating target of mTORC1, appears to be the candidate in the mTORC1 signaling pathway that can phosphorylate Rictor. ${ }^{81}$ The Rictor phosphorylation does not affect mTORC2 integrity or in vitro kinase activity, however, phosphorylation of this site modulates the binding of Rictor and mTORC2 with protein 14-3-3, which is rapamycin sensitive. ${ }^{82}$ The expression of a site mutant of Rictor (T1135A) in either wild-type or Rictor null cells causes an increase in the mTORC2-dependent phosphorylation of Akt on serine 473, suggesting that Rictor-T1135 phosphorylation by mTORC1-dependent mechanisms regulates the activation of mTORC2..$^{81,83}$

\section{The Function of mTOR Complex}

In response to growth factor, mitogen, nutrient and stress, mTORC1 has been well established to regulate cell growth and cell proliferation. Induction of protein and lipid synthesis has been considered the driving factor for mTORC1 to promote cell growth. ${ }^{13,84,85}$ The mTORC1 initiates cap-dependent protein translation, a rate-limiting step of protein synthesis, through phosphorylating its two major downstream targets p70S6K and
4EBP $1 .{ }^{86}$ Multiple phosphorylation sites have also been found on the serine and threonine residues of $\mathrm{P} 70 \mathrm{~S} 6 \mathrm{~K}$, however, phosphorylation of threonine 389 residue by mTOR is critical for p70S6K activation and serves as a marker for mTOR activity. ${ }^{87}$ Upon activation, mTORC1 is recruited to the eukaryotic initiation factor3 (elF3) translation initiation complex at the 5'-methylguanosine cap of mRNAs, where p70S6K is bound, and then directly phosphorylates $\mathrm{p} 70 \mathrm{~S} 6 \mathrm{~K},{ }^{88}$ resulting in its dissociation with elF3 complex, activation and subsequent phosphorylation of its translational targets. In contrast, phosphorylation of 4EBP1 (threonine 37/46, serine 65 and threonine 70 ) results in its inactivation and the loss of its ability to bind to an initiation factor elF4E, enabling cap-dependent translation. ${ }^{89-91}$ In addition, mTORC1 can also regulate growth factor induced activation of mitogenactivated protein kinase ( $\mathrm{p} 44 / 42)$ through protein phosphatase 2A (PP2A). ${ }^{84}$ The critical roles of $\mathrm{p} 44 / 42$ in growth factor mediated transcription, DNA replication and protein translation have been well recognized.

The cytoskeleton organization regulation is the primary function of mTORC2. ${ }^{92}$ mTORC2 has also been involved in the regulation of cells survival and cell cycle progression. ${ }^{22,93-98}$ mTORC2 may signal to the actin cytoskeletin through protein kinase $\mathrm{C}$ (PKC) by phosphorylating and activating $\mathrm{PKC}^{99}$ and also may through Akt signaling pathway involving Rho GTPase. ${ }^{23,92,100}$ Expression of constitutive active forms of the Rho GTPases promotes organization of the actin skeleton and prevents the actin defect due to loss of mTORC2 function.

\section{The Role of mTOR Complex in the Nervous System}

Synaptic plasticity. In the CNS, mTOR has been involved in synaptic plasticity. Synaptic plasticity is the alteration of the strength of connections among neurons, which is considered as the mechanism for memory storage in the CNS. Synapse is the basic unit that is essential for the communication between neurons and can be potentiated by repeated activity or response. Synaptic transmission between axons and dendrites in neurons is a measure of communication at synapses. Two forms of lasting synaptic plasticity, long-term potentiation (LTP) and longterm depression (LTD) of excitatory synaptic transmission, are widely expressed at excitatory synapse in the mammalian brain. In the long lasting forms of synaptic plasticity, altered translational control and protein synthesis play a critical role in synaptic plasticity. 9,101

As a principal modulator of translation, mTOR has been associated with the regulation of synaptic plasticity. The target proteins of mTOR, 4EBP1 and eukaryotic initiation factor-4E (eIF4E), have been detected in the cell bodies and dendrites in cultured hippocampal neurons and their distribution completely overlaps with a postsynaptic density protein-95 (PSD-95) at synaptic sites, suggesting that the postsynaptic localization of these proteins. Rapamycin application results in a reduction of late-phase LTP expression and also blocks the synaptic potentiation induced by brain-derived neurotrophic factor (BDNF). ${ }^{102}$ Downstream of BDNF, mTOR mediated mRNA translation and synaptic glutamate receptor (GluR)1 expression that is required for memory consolidation. ${ }^{103}$ 
The study demonstrates that consolidation of inhibitory avoidance long-term memory (IALTM) in rats entails mTOR activation in the dorsal hippocampus after training increase in AMPA receptor GluR1 subunit expression, which is inhibited by mTOR inhibitor rapamycin. In addition, either pre- or post-training, administration of anti-BDNF antibodies into dorsal CA1 impairs IALTM retention and abolishes the learning-induced biphasic activation of mTOR and p70S6K and blocks GluR1 expression, suggesting that mTOR signaling has a role downstream of BDNF in controlling fear-memory consolidation. ${ }^{103}$

Activation of the PI 3-K/Akt-mTOR signaling pathway has been involved in fear memory retention. High-frequency stimulation induces LTP, resulting in the phosphorylation of Akt (at the serine 473 residues), mTOR, p70S6K and 4EBP1, which is inhibited by the infusion of PI $3-\mathrm{K}$ inhibitors (wortmannin and LY294002) and an mTOR inhibitor (rapamycin) into the medial prefrontal cortex, a crucial neural locus for the control of cognition and emotion. Inhibition of PI 3-K and mTOR also interferes with the long-term retention of trace fear memory but not with short-term trace fear memory and object recognition memory. ${ }^{104}$ Systemic inhibition of mTOR by rapamycin also weakens the traumatic fear memory reconsolidation and inhibits the contextual fear memory, ${ }^{105,106}$ suggesting the potential application of mTOR inhibition for posttraumatic stress disease and other acquired anxiety. Physical stress evoked by tail shock in rats induces a profound and prolonged phosphorylation of PDK1, Akt, mTOR, p70S6K and eIF4B in hippocampal CA1 homogenate, which is prevented by the PI $3-\mathrm{K}$ inhibitor. ${ }^{107}$ Further study indicates that stress also upregulate the dendritic scaffolding protein PSD-95, which is involved in the formation of LTP and LTD, in an mTOR-dependent manner. These results suggest a key role of PI 3-K/mTOR signaling in mediating the stress induced modification of hippocampal synaptic plasticity may through invoking the protein expression of PSD-95. ${ }^{107}$

Neuroendocrine. The role of $\mathrm{mTOR}$ in the regulation of neuroendocrine through the hypothalamic axis has also been described. Hypothalamic mTOR signaling regulates food intake and acts as a cellular fuel sensor to energy status. ${ }^{108}$ mTOR signaling is controlled by energy status in the arcuate nucleus of the hypothalamus. Central administration of leucine increases hypothalamic mTOR signaling and decreases food intake and body weight. The hormone leptin that has proanorectic effect increases hypothalamic mTOR activity, the inhibition of which by rapamycin reduces leptin's anorectic effect. Central mTOR also controls gonadotropic axis and the onset of puberty. ${ }^{109}$ Central activation of mTOR can stimulate leuteinizing hormone secretion and the blockade of central mTOR signaling by rapamycin causes inhibition of the gonadotropic axis at puberty, revealing delayed vaginal opening, decreased LH and estradiol levels and ovarian and uterine atrophy. Inactivation of mTOR also blunts the positive effects of leptin on puberty onset in food-restricted females. The gonadotropic effects of mTOR may acquire through the regulation of Kiss1 expression in the arcuate nucleus of the hypothalamus. ${ }^{109}$ The expression of Kiss1 has been suggested to regulate the hypothalamic reproductive axis and puberty. ${ }^{109-111}$ Inhibition of mTOR evokes a significant decrease of Kiss1 expression at the hypothalamus, with dramatic suppression of Kiss1 mRNA levels at the arcuate nucleus. ${ }^{109}$

Neuroregeneration. Axon regeneration has been involved synthesis of raw material and axonal compartment by the neuronal soma and therefore translational control of protein synthesis plays an important role in the process of axon regeneration. ${ }^{112-115}$ As a major translational regulator, mTOR may acquire the ability to regulate neuronal regeneration. The ability of sensory and retinal axon to regenerate in vivo correlates with the capability of forming a new growth cone after axotomy in vitro and axonal protein synthesis and degradation are necessary for growth cone regeneration. ${ }^{116}$ Interestingly, inhibition of mTOR, p38 mitogenactivated protein kinase (MAPK) and caspase 3 represses growth cone formation, suggesting that mTOR, p38MAPK and caspase 3 associated protein synthesis and degradation initiates growth cone formation after axotomy. ${ }^{116}$

The PTEN/mTOR signaling has been recently implicated in neuronal regeneration. Phosphatase and tensin homolog (PTEN) appears to be a critical regulator of PI 3-K signaling. PTEN can dephosphorylate tyrosine-, serine- and threonine phosphorylated peptides and negatively regulates PI 3-K pathways by specifically dephosphorylating $\mathrm{PIP}_{2}$ and $\mathrm{PIP}_{3}$ at the $\mathrm{D} 3$ position. ${ }^{117}$ As a result, a reduction in the membrane phospholipid pool that is necessary for the recruitment of Akt can ensue during PTEN activation. ${ }^{117-119}$ The activation of $\mathrm{mTOR}$ is the downstream of PI 3 -K/Akt activation in response to growth factors as mentioned in proceeding sections and therefore PTEN is also a negative regulator of mTOR. Deletion of PTEN in adult retinal ganglion cells (RGCs) and in corticospinal neurons promotes robust axon regeneration after optic nerve injury and spinal cord injury respectively. ${ }^{120}$ In wild-type adult mice, the regeneration failure may be contributable to the suppression of mTOR activity and new protein synthesis in axotomized RGCs, since reactivating this pathway by conditional knockout of TSC1, which negatively regulate the mTOR pathway, leads to axon regeneration. ${ }^{115}$ In cortical neurons, mTOR activity is downregulated during development and further diminishes after axotomy, ${ }^{120}$ suggesting downregulation of mTOR contributes to the lost of the ability of axon to regenerate in the CNS after injury.

Yet, neurotrophins induced mTOR signaling pathway may interfere the axon regeneration through the modulation of astrocyte response to the CNS injury. The CNS damage activates astrocytes and the reactive astrocytes upregulate the expression of intermediate filament proteins that inhibit axonal growth. Over time, reactive astrocytes deposit extracellular matrix molecules and form a glial scar. The glial scar, in one aspect, plays an important role in the repair process, ${ }^{121}$ but the glial scar also represents a physical barrier that interferes the regeneration of damaged axon. ${ }^{122-126}$ Therefore, limiting astrocytic responses represents a potential therapeutic strategy to improve functional recovery after CNS injury. The epidermal growth factor (EGF) receptor is upregulated in astrocytes after injury and EGF promotes the transformation of astrocytes into reactive forms may through an mTOR associated pathway. ${ }^{121}$ The inhibition of EGF receptor enhances axon regeneration in the injured optic nerve and promotes recovery after spinal cord injury. In cultures of 
adult spinal cord astrocytes, EGF activates the mTOR pathway through Akt-mediated phosphorylation of the GAP. Further study indicates that Rheb is required for EGF-dependent mTOR activation in spinal cord astrocytes. Moreover, elevated levels of activated EGF receptor and mTOR signaling in reactive astrocytes in vivo in an ischemic model of spinal cord injury was observed and EGF-dependent chemoattraction of astrocytes was inhibited by rapamycin, suggesting that inhibition of mTOR signaling could limit astrocytic responses in the damaged nervous system and may be beneficial to axon regeneration. ${ }^{121}$ As a result, the regulation of mTOR activating level is very important for neuroregeneration in the CNS.

As a result, comparing to the CNS, the axons in the peripheral nerve system (PNS) seems to have a more robust ability to regenerate after injury since they have fewer barrier that influences the axon regeneration, however, the recovery after injury of the peripheral neurons is still limited. Activation of mTOR has been reported in dorsal root ganglial neurons (DRGs) following injury and inhibition of mTOR by rapamycin blocks the axon regeneration, suggesting that $\mathrm{mTOR}$ activation enhances axonal growth capacity. ${ }^{127}$ Moreover, genetic upregulation of mTOR activity by deletion of TSC2 in DRGs is sufficient to enhance axonal growth capacity in vitro and in vivo. The regeneration promoting effect of mTOR activity may associate with synthesis of growth associated protein-43 (GAP-43), a crucial component of axonal outgrowth. ${ }^{127}$

Neurodegenerative diseases. Alzheimer disease (AD) is a progressive neurodegenerative disorder with cognitive dysfunction and loss of memory. The National Institute on Aging estimates that almost five million people have AD in the United States. Furthermore, more than twenty-four million people suffer from $\mathrm{AD}$, pre-senile dementia, and other disorders of cognitive loss worldwide. $\mathrm{AD}$ is characterized by two pathologic hallmarks that consist of extracellular plaques of amyloid- $\beta(A \beta)$ peptide aggregates and intracellular neurofibrillary tangles composed of hyperphosphorylated microtubular protein tau. ${ }^{40,128,129}$ The $\beta$-amyloid deposition that constitutes the plaques is composed of a 39-42 amino acid peptide, which is the proteolytic product of the amyloid precursor protein (APP) ${ }^{130-132}$ In $\mathrm{AD},{ }^{133} \mathrm{~A} \beta$ is toxic to cells, ${ }^{134-138}$ can lead to oxidative stress, ${ }^{40,139,140}$ and result in cell death..$^{141-144}$

Oxidative stress occurs through the generation of reactive oxygen species (ROS) that consist of oxygen free radicals and other chemical entities. ${ }^{145-147}$ Oxygen free radicals can be generated in elevated quantities during the reduction of oxygen and lead to cell injury. ROS can involve superoxide free radicals, hydrogen peroxide, singlet oxygen, nitric oxide (NO) and peroxynitrite. ${ }^{40,132,139,148}$ Oxidative stress may be tempered by different vitamins, such as vitamin $\mathrm{D}_{3}{ }^{149}$ and the amide form of niacin or vitamin $\mathrm{B}_{3}$, nicotinamide. ${ }^{150-156}$ Oxidative stress leads to the destruction of multiple cell types through apoptotic pathways ${ }^{157-159}$ and also through autophagy. ${ }^{160}$ Apoptotic induced oxidative stress in conjunction with processes of mitochondrial dysfunction ${ }^{161-164}$ can contribute to a variety of disease states such as diabetes, ${ }^{165-168}$ ischemia, cognitive loss, AD, ${ }^{40,139,140}$ Parkinson disease, ${ }^{139,169}$ sepsis, ${ }^{170,171}$ Huntington disease, ${ }^{139,172}$ acute ${ }^{173-175}$ traumatic and chronic injuries, ${ }^{40,139,176-178}$ and immune dysfunction. ${ }^{179-181}$ Oxidative stress can lead to apoptosis in neurons, endothelial cells (ECs), cardiomyocytes ${ }^{148,182-186}$ and smooth muscle cells that involve separate as well as overlapping pathways..$^{176,187-191}$

Dysfunction of mTORC1 has been associated with both of the pathogenic mechanisms of AD (Table 2). The activation of p70S6K, downstream of mTORC1, has been identified as a contributor to hyperphosphorylated tau accumulation in neurons with neurofibrillary tangles. ${ }^{192}$ Significant increase in the level of phosphorylated mTOR (serine 2448 and serine 2481) and tau (serine 214) has been detected in AD neurons. ${ }^{193,194}$ Alteration of mTOR level in lymphocyte of AD patients correlates with memory and cognitive decline. ${ }^{195}$ The level of activated p70S6K is significantly reduced in lymphocytes of $\mathrm{AD}$ patients, and is statistically correlated with Mini Mental Status Examination scores. ${ }^{196}$ These findings demonstrate that alteration of mTOR/ p70S6K signaling could contribute to the pathogenesis of AD.

Yet, the major pathogenic agent of $A D, A \beta$ seems to downregulate the mTORC1 signaling pathway and inhibition of mTOR by rapamycin enhances $A \beta$ induced cell death, suggesting that mTOR provides cell protection against $A \beta$ toxicity. ${ }^{196} A \beta$ also produces a rapid and persistent downregulation of mTOR/ p70S6K phosphorylation in murine neuroblastoma cells associated with caspase 3 activation in the cortex of double APP/PS1 transgenic mice compared with control mice. ${ }^{196}$ The mTOR signaling is inhibited in hippocampal slice of wildtype mice upon exposure to $A \beta$ and the downregulation of mTOR signaling has also been observed in both cultured neurons and hippocampal slice from AD transgenic mice. ${ }^{197}$ The dysregulation of mTOR induced by $\mathrm{A} \beta$ correlates with the impairment of synaptic plasticity, which is rescued by pharmacological or genetic upregulation of mTOR signaling. ${ }^{197}$ However, recently, inhibition of mTOR by rapamycin was shown to reduce the level of $A \beta$ and improve the cognitive function in a mouse model of $\mathrm{AD} .{ }^{198}$ To review the above information, controversial results concerning the relation between mTOR signaling and the progression of AD exist and thereby further study is necessary to confirm the definite function of mTOR signaling in AD.

In addition, the mTOR signaling may also associate with neuronal atrophy in $\mathrm{AD}$ involving insufficiency of retinoblastoma tumor suppressor (RB1) inducible Coiled-Coil 1 (RB1CC1). RB1CC1 expresses in many tissues, including skeletal muscles, heart, kidneys and neurons, and plays an important role in cell size control. ${ }^{199,200}$ The abundance of RB1CC1 has been found to maintain the level of RB1 and mTOR contributing to the non-proliferating enlarged cell phenotype in neuromuscular tissues. ${ }^{199}$ RB1CC1 introduction into Neuro-2a neuroblastoma cells enhances neurite growth. In contrast, RNAi-mediated knockdown of RB1CC1 or rapamycin treatment causes neurite atrophy and apoptosis in the differentiated Neuro-2a cells. ${ }^{201}$ In the brains of AD patients, the balance between TSC 1 and RB1CC1 seems to be required for cells to maintain mTOR signaling activation, since lack of RB1CC1 expression, which is less than TSC1, causes mTOR signaling repression and neuronal atrophy. ${ }^{201}$ These findings suggest that RB1CC1 insufficiency may result in mTOR signaling repression through unbalanced 
Table 2. Implications of mammalian target of rapamycin (mTOR) signaling in neurological diseases

\begin{tabular}{|c|c|c|}
\hline Neurological diseases & Potential implication of mTOR signaling & References \\
\hline Alzheimer disease (AD) & $\begin{array}{l}\text { p-mTOR and p-4EBP1increased in AD neurons, correlating with increased } \\
\text { hyperphosphorylated tau } \\
\text { p-p70S6K increased in lymphocytes correlating with cognitive impairment }\end{array}$ & $\begin{array}{l}\text { Griffin, et al. 2005; Li, et al. 2005; } \\
\text { Lafay-Chebassier, et al. } 2005\end{array}$ \\
\hline Parkinson disease & $\begin{array}{l}\text { mTORC1 activation potentiates dyskinesia } \\
\text { mTOR activation prevents oxidative stress induced dopaminergic neuronal death }\end{array}$ & $\begin{array}{l}\text { Santini, et al. 2009; } \\
\text { Choi, et al. } 2010\end{array}$ \\
\hline Huntington disease & $\begin{array}{l}\text { Inhibition of mTOR induces autophagy, increases the clearance of mutant } \\
\text { huntingtin aggregate, and prevents huntingtin fragment toxicity }\end{array}$ & $\begin{array}{l}\text { Floto, et al. 2007; } \\
\text { Ravikumar, et al. } 2003\end{array}$ \\
\hline $\begin{array}{l}\text { Neurofibromatosis type } \\
\qquad \text { I (NF1) }\end{array}$ & $\begin{array}{l}\text { Nf1 mutant increases the activity of mTOR, inhibition of which suppresses NF1 } \\
\text { associated tumorigenesis }\end{array}$ & $\begin{array}{l}\text { Dasgupta, et al. 2005; Hegedus, et al. } \\
\text { 2008; Johannessen, et al. } 2008\end{array}$ \\
\hline Fragile $X$ syndrome & $\begin{array}{l}\text { FMR1 knockout in mice increases mTOR activity and p70S6K activation; p70S6K } \\
\text { can phosphorylate FMRP }\end{array}$ & $\begin{array}{l}\text { Sharma, et al. } 2010 \text {; } \\
\text { Narayanan, et al. } 2008\end{array}$ \\
\hline Epilepsy & $\begin{array}{l}\text { Inhibition of mTOR reduces seizure in TS mouse model, prevents acquired } \\
\text { seizure, and reduces chronic spontaneous seizure activity }\end{array}$ & $\begin{array}{l}\text { Meikle, et al. 2008; Zeng, et al. 2008; } \\
\text { Zeng, et al. 2009; Huang, et al. } 2010\end{array}$ \\
\hline Ischemic stroke & $\begin{array}{l}\text { Rapamycin potentiates OGD induced injury in microglia and neurons } \\
\text { Deletion of p70S6K enhance OGD induced apoptosis in astrocytes }\end{array}$ & $\begin{array}{l}\text { Chong, et al. 2007; Figure } 2 \\
\text { Pastor, et al. } 2009\end{array}$ \\
\hline
\end{tabular}

4EBP1, eukaryotic initiation factor $4 \mathrm{E}$-binding protein 1; FMRP, fragile $\mathrm{X}$ syndrome mental retardation protein; OGD, oxygen glucose deprivation; p70S6K, p70 ribosomal S6 kinase; PI 3-K, phosphoinositide 3-kinase; p-4EBP, phosphorylated 4EBP; p-p70S6K, phosphorylated p70S6K.

TSC1 abundance leading to neuronal atrophy, which may be linked to the pathogenesis of AD.

Parkinson disease (PD) is a movement disorder characterized by resting tremor, rigidity and bradykinesia. The pathophysiological basis of the symptoms rests upon the degeneration of dopaminergic neurons in the substantia nigra (SN). In some scenarios, it has been hypothesized that dopamine may even be a culprit in precipitating disease progression. ${ }^{139,163,202}$

The activity of mTOR has been associated with PD through a stress response protein RTP801. The stress response gene RTP801 can be induced by DNA damage and oxidative stress ${ }^{203,204}$ which has been linked to the pathogenesis of PD. RTP801 is highly induced in several cellular models of PD such as treatment with 6-hydroxydopamine (6-OHDA), $\mathrm{MPP}^{+}$and rotenone. ${ }^{205}$ Moreover, RTP801 is also induced in an animal model of PD and is elevated in dopaminergic neurons of PD patients. Short hairpin RNA (shRNA) knocking out RTP801 is protective against 6-OHDA application in cellular model of PD. These findings suggest that RTP801 as a potential contributor to neuronal degeneration in PD. Interestingly, RTP801 is a negative regulator of mTOR, working downstream of Akt and upstream of TSC2 to inhibit mTOR activity. ${ }^{203}$ RTP801 and 6-OHDA trigger neuronal death by suppressing activation of mTOR. The logic sequence is that PD-associated stresses induce RTP801, suppress mTOR signaling and induce neuronal degeneration and death. ${ }^{206}$ Yet, the activation of mTOR may potentiate dyskinesia during treatment. In a mouse model of $\mathrm{PD}$, administration of 1-DOPA results in the activation of the mTORC1 in a dopamine receptor dependent manner, which is occurred selectively in the GABAergic neurons that project directly from the striatum to the output structures of the basal ganglia. The 1-DOPA-mediated activation of mTORC1 persists in mice that have developed dyskinesia and the mTORC1 inhibitor rapamycin prevents the development of dyskinesia without affecting the therapeutic efficacy of 1-DOPA. ${ }^{207}$

Oxidative stress has been closely associated with dopaminergic neurodegeneration ${ }^{208,209}$ and a neuroprotective protein Oxi-alpha has been shown to be downregulated in dopamine neurons during oxidative stress. ${ }^{210}$ Oxi-alpha protects dopaminergic neurons against autophagic cell death induced by oxidative stress, in contrast, Oxi-alpha knockdown increases the vulnerability of neurons to oxidative insult. Moreover, the downregulation of Oxi-alpha by knockdown suppresses the activation of mTOR signaling exhibiting a decrease in the level of the mTOR kinase activity and phosphorylation of $\mathrm{p} 70 \mathrm{~S} 6 \mathrm{~K}$ and $4 \mathrm{EBP} 1$. These results indicate that dysfunction of mTORC1 signaling is involved in the pathogenesis of $\mathrm{PD}$, suggesting that targeting $\mathrm{mTORC} 1$ signaling pathway may be a promising strategy for the treatment of PD (Table 2).

Huntington disease (HD) is an autosomal dominant neurodegenerative disease characterized by impairment of involuntary movement and cognitive impairment. Selective loss of neurons in the basal ganglia and cerebral cortex is one of the anatomical hallmarks of this disease. Genetically, HD is caused by CAG trinucleotide repeat expansion mutations that are translated into abnormally long polyglutamine tracts. ${ }^{211,212}$ The HD gene encodes a protein called huntingtin and the disease is associated 
with expansions of more than 37 consecutive glutamines that are found close to its N-terminus.

The mTOR signaling may impact on the polyglutamine toxicity by autophagy (Table 2). Autophagy is the process by which cells recycle cytoplasmic components and dispose of defective organelles. The process includes a bulk degradation of cytoplasmic material during nutrient deficiency or other conditions and subsequent sequestration of the cytoplasm including protein and organelles into autophagsomes that fuse with or are imported into lysosomes for degradation and reused by essential cellular process. ${ }^{213}$ Autophagy can occurs at basal levels in most tissues and can also be induced by the variety of environmental conditions such as nutrient depletion and injury. In addition to turnover of cellular components, autophagy has been implicated in development, differentiation and tissue remodeling in various organisms. Autophagy has also been linked to a growing number of diseases, such as cancer, infectious diseases and neurodegenerative diseases. ${ }^{214-219}$ Autophagy can serve a double-edged sword that is protective or detrimental to cells.

In the CNS, autophagy may function as a major mechanism underlying the degradation and clearance of aggregate-prone, intracytosolic proteins causing neurodegenerative disorders, such as HD. As a result, enhancing autophagy is a potential therapeutic strategy for clearing these disease-causing proteins. ${ }^{220}$ The key role of mTOR signaling in the regulation of autophagy had been established long time ago ${ }^{221}$ and confirmed by extensive investigations. $^{222}$ In HD, mTOR is sequestered in polyglutamine aggregates in cell models, transgenic mice and human brains, impairing its kinase activity and inducing autophagy. The specific inhibitor of mTOR rapamycin can enhance the autophagic clearance of proteins with long polyglutamines and a polyalanine-expanded protein and reduces their toxicity. ${ }^{223}$ Rapamycin also attenuates huntingtin accumulation and cell death in cell models of HD and protects against neurodegeneration in a fly model of HD. ${ }^{223,224}$ In addition to rapamycin, some small molecular enhancers of rapamycin induce autophagy with both mTOR dependent and independent mechanisms in mammalian cells and enhance the clearance of a mutant huntingtin fragment in a HD cellular model and also protects against a mutant huntingtin fragment toxicity in Drosophila. ${ }^{25}$ The rapamycin analog CCI779 improves behavioral performance and decreases aggregate formation in a mouse model of HD. ${ }^{224}$ In this regard, inhibitors of mTOR may be regarded as potential therapeutic agents in aggregate diseases including $\mathrm{HD}$.

Glucose/glucose-6-phosphate has been identified as a novel stimulus for autophagy via mTOR and Akt and this leads to enhanced clearance of the toxic huntingtin exon 1 fragment. ${ }^{226,227}$ Raised intracellular glucose level in HD cell models increases clearance of mutant huntingtin correlating with increased autophagy and reduced phosphorylation of mTOR, p70S6K1 and Akt. Thus, raised intracellular glucose and the consequence of glucose 6-phosphate level reduce mutant huntingtin toxicity through autophagy by using a mechanism that is associated with modulation of mTOR signaling. ${ }^{226}$

Genetic diseases. Tuberous sclerosis (TS) is a multi-organ disorder including the brain caused by heterozygous mutations in the TSC1 or TSC2 gene and is often associated with neuropsychiatric symptoms, including intellectual disability, specific neuropsychological deficits, autism, other behavioral disorders and epilepsy. ${ }^{228}$ In the brain, tuberous sclerosis complex (TSC) is associated with cortical tubers consisting of giant cells, dysmorphic neurons and astrocytes. The TSC1 and TSC 2 genes encoded proteins form TSC1/TSC2 complex which functions to regulate protein synthesis and cell growth by inhibiting mTORC1 mediated signaling pathway. ${ }^{229}$ In addition, skin lesion is one of the characteristic features in TS. In cultured fibroblasts from healthy skin of a TS patient, the upregulation of p70S6 ribosomal protein was found, suggesting enhancing activity of mTORC1 in TS. ${ }^{230}$

Given the role of mTORC1 signaling downstream of TSC1/ TSC2 complex, it is not surprised to find that application of rapamycin and RAD001 [40-O-(2-hydroxyethyl)-rapamycin] improves the median survival from $33 \mathrm{~d}$ to more than $100 \mathrm{~d}$ and also improves the behavior, phenotype and weight gain with reduced levels of phospho-p70S6K, a downstream target of mTORC1, in a mouse neuronal model of $\mathrm{TS}^{229}$ (Table 2). Rapamycin treatment can significantly improves facial angiofibroma lesion in TS patients, which affects $70-80 \%$ of patients with TS, typically on the face. ${ }^{231}$ Both mTORC1 blockade alone by RAD001 and combined PI 3-K-mTOR blockade by pan class I PI 3-K/mTOR catalytic small molecule inhibitor NVP-BEZ235 leads to suppression of kidney tumor development in a mouse TS model. ${ }^{232}$

The elevation of both endoplasmic reticulum and oxidative stress has been observed in TSC2 deficient rat hippocampal neurons and brain lysates from a TSC1 deficient mouse. Neurons lacking functional TSC1/TSC2 have increased vulnerability to endoplasmic reticulum stress induced cell death, suggesting that oxidative stress may contribute to the neuronal dysfunction in TS. ${ }^{233}$ More importantly, the mTOR inhibitor rapamycin prevents oxidative stress in TSC1/TSC2 dysfunctional neurons. As a result of above studies, targeting mTORC1 signaling pathway may represent a therapeutic strategy against TS.

Neurofibromatosis type 1 (NF1) is a common autosomal dominant tumor predisposition syndrome characterized by formation of neurofibromas and astrocytoma (glioma). The NfI gene encodes neurofibromin, an inhibitor of RAS signaling and a mutation of $N F 1$ gene disrupt neurofibromin synthesis resulting in the activation of RAS followed by upregulation of PI 3-K and mTOR activity. The Nfl-deficient astrocytes exhibit high levels of mTOR activity revealed by high level of p70S6K phosphorylation, which is inhibited by blocking K-RAS or PI 3-K activation in both $N f 1$ mutant mouse optic nerve gliomas and in human NF1-associated pilocytic astrocytoma tumors. ${ }^{234}$ Moreover, inhibition of mTOR signaling in $N f 1^{-/-}$astrocytes abrogates their growth advantage in culture, restoring normal proliferative rate. ${ }^{234}$ In genetically engineered mouse models of low-grade glioma, pharmacologic inhibition of mTOR reduces tumor cell proliferation and tumor volume in a dose dependent manner. ${ }^{235}$ mTORC1 activity has been found to be essential for NF1 associated tumorigenesis. ${ }^{236}$ The mTOR inhibitor rapamycin potently suppresses the growth of aggressive NF1-associated malignancies in a genetically engineered murine model of NF1 through suppressing the mTOR target cyclin D1. ${ }^{236}$ These results suggest that 
mTORC1 associated signaling pathway may represent a logical therapeutic target for brain tumors in NF1 (Table 2).

Fragile $\mathrm{X}$ syndrome is the most common form of inherited mental retardation caused by transcriptional silencing of FMRI gene encoding the fragile $\mathrm{X}$ mental retardation protein (FMRP). FMRP is an RNA binding protein preventing the translation in neurons through binding to mRNA. ${ }^{237}$ Posttranslational modification of FMRP has also been associated with modulation of protein synthesis. Non-phosphorylated FMRP associates with actively translating polyribosomes, whereas phosphorylated FMRP (primarily at serine 499) is found in potentially stalled ribosomes. ${ }^{238}$ The cognitive deficit and group I metabotrophic glutamate receptor (mGluR) dependent LTS exaggeration has been found in the most commonly used $R M R 1$ knockout mouse model of fragile X syndrome. ${ }^{239}$ FMRP is dephosphorylated immediately following stimulation of group I mGluR by protein phosphatase 2A (PP2A), however, longer stimulation of group I mGluR rephosphorylate FMRP in a PP2A and mTOR dependent manner. Further study has identified the downstream target of mTORC1, p70S6K, as a major FMRP kinase in the mouse hippocampus, which can phosphorylate FMRP and mediate the mGluR induced FMRP phosphorylation. ${ }^{240}$ More importantly, the dysfunction of mTORC1 signaling has been found in fragile X syndrome. The FMR1 knockout mouse exhibits increased mTOR phosphorylation and signaling, including an increased association of Raptor with mTOR, a elevation in mTOR kinase activity, and an increase in the level of phosphorylation of mTOR downstream targets $\mathrm{p} 70 \mathrm{~S} 6 \mathrm{~K}$ and $4 \mathrm{EBP}$ and formation of eukaryotic initiation factor complex $4 \mathrm{~F}$ (eIF4F) (Table 2).

Traumatic brain injury. In response to traumatic brain injury (TBI), neurons initiate neuroplastic processes through the activation of intracellular signaling pathways; activation of mTOR signaling may represent one of these mechanisms. In a fluidpercussion brain injury model, rats received moderate injury on the right side of parietal cortex, the mTOR, p70S6K and 4EBP1 phosphorylation levels were significantly increased in the ipsilateral parietal cortex and hippocampus from $30 \mathrm{~min}$ to $24 \mathrm{~h}$ after TBI, whereas total protein levels were unchanged. In accordance with these results, eIF4E, a key rate-limiting mRNA translation factor, was also phosphorylated by mitogen-activated protein kinase-interacting kinase 1 (Mnk1) $15 \mathrm{~min}$ after TBI. These results suggest that changes in mRNA translation associated with activation of mTOR signaling pathway may be one mechanism that neurons use to respond to TBI and may contribute to the neuroplasticity during trauma in the brain. ${ }^{241}$ But, the exact effects of mTOR signaling activation remain elusive. Yet, in a closed head injury model in mice, rapamycin injection $4 \mathrm{~h}$ following the onset of injury significantly improves functional recovery as manifested by changes in the Neurological Severity Score accompanied by decreased level of p70S6K phosphorylation, microglia/macrophages activation and increased number of surviving neurons at the site of injury. ${ }^{242}$ Interestingly, with ATP administration in a spinal cord injury model, a significant increase in activated Akt $/ \mathrm{mTOR} / \mathrm{p} 70 \mathrm{~S} 6 \mathrm{~K}$ signaling pathway was accompanied by improved locomotor function after injury, which is inhibited by rapamycin treatment, indicating that the induction of $\mathrm{Akt} / \mathrm{mTOR} / \mathrm{p} 70 \mathrm{~S} 6 \mathrm{~K}$ activation by ATP produces a beneficial effect on motor function recovery after spinal cord injury ${ }^{243}$ (Table 2).

Epilepsy. Epilepsy is a common chronic neurological disorder. Epilepsy is characterized by recurrent seizures that are unpredictable and sometimes progressively severe. Epilepsy is also associated with significant mortality and morbidity. The mTOR signaling pathway has been implicated in epilepsy in TS. One of common neurological manifestations of TS is epilepsy that occurs in over $80 \%$ of TS patients. ${ }^{244}$ Mutations of TSC1 and TSC2 that act upstream of the mTOR leads to a high incidence of epilepsy. ${ }^{245}$ Rapamycin treatment that inhibits the mTOR pathway attenuates structural abnormalities and reduces seizures in TS mouse models, ${ }^{229,246}$ suggesting that the aberrant mTOR activation interferes with normal brain development and leads to epilepsy. The mTOR signaling activation has also been linked to acquired epilepsy and pharmacological inhibition of the mTOR pathway, either before or immediately following neurological insults, can prevent pathological changes in animal brains and the development of spontaneous recurrent seizure in an acquired epilepsy model. ${ }^{247}$ Furthermore, chronic hippocampal infusion of the mTOR inhibitor rapamycin reduces mossy fiber sprouting in a rat pilocarpine model of temporal lobe epilepsy. ${ }^{248}$ The mTOR is hyperactivated in rat brains with chronic spontaneous seizures and inhibition of the mTOR pathway by rapamycin markedly reduces chronic spontaneous seizure activity, along with inhibition of mossy fiber sprouting. ${ }^{249}$ Therefore, mTOR activated signaling pathway could represent a potential therapeutic target for epilepsy (Table 2).

Ischemic stroke. Ischemic stroke is a leading cause of serious, long-term disability in the developed countries, but the effective approach for management in patients is limited. To restore the blood flow of the brain by using t-PA is the only approved treatment for ischemic stroke in the United States, yet it may thereby induce reperfusion-induced injury to neurons. As a result, to find novel approaches to increase the resistance of neurons to reperfusion-induced injury is still tough task for patients with ischemic stroke. With further work and insight into novel therapeutic mechanisms against ischemic brain injury may bring more practical approaches for the management of ischemic stroke.

Apoptosis has been closely associated with neuronal loss in ischemic brain injury and consists of both the early exposure of membrane phosphatidylserine (PS) residues and the late destruction of genomic DNA. ${ }^{128,250}$ Externalization of membrane PS residues is an early event during cell apoptosis, ${ }^{251,252}$ can become a signal for the phagocytosis of cells that is controlled by caspase 1 and caspase $3,{ }^{38,159,253}$ and control cell proliferation. ${ }^{37,179-181,189,254}$ The loss of membrane phospholipid asymmetry leads to the exposure of membrane PS residues on the cell surface and assists microglia to target cells for phagocytosis. . $^{37,156,189,255,256}$ This process occurs with the expression of the phosphatidylserine receptor (PSR) on microglia during oxidative stress. ${ }^{202,257}$ It has been shown that blockade of PSR function in microglia prevents the activation of microglia. ${ }^{37,258}$ Externalization of membrane PS residues occurs in neurons, vascular cells and inflammatory microglia during reduced oxygen exposure, ${ }^{159,259,260} \beta$-amyloid (A $\beta$ ) exposure, ${ }^{135,179}$ nitric oxide exposure, ${ }^{261-265}$ and during the administration of 
agents that induce the production of reactive oxygen species, such as 6-hydroxydopamine. ${ }^{266}$ Membrane PS externalization on platelets also has been associated with clot formation in the vascular system. ${ }^{267}$

The cleavage of genomic DNA into fragments ${ }^{259,268,269}$ usually occurs after membrane PS exposure ${ }^{187}$ and is considered to be a later event during apoptotic injury. ${ }^{189,269-271}$ Several enzymes responsible for DNA degradation include the acidic, cation independent endonuclease (DNase II), cyclophilins and the 97 kDa magnesium-dependent endonuclease. ${ }^{139,272}$ Three separate endonuclease activities also have been found in neurons that include a constitutive acidic cation-independent endonuclease, a constitutive calcium/magnesium-dependent endonuclease and an inducible magnesium dependent endonuclease. ${ }^{273,274}$

Although ischemic neurons often die from necrosis, a large amount of neurons may succumb to apoptosis and subsequently result in the loss of neurons if there is no salvaging measure. The development of neuronal apoptosis has been demonstrated following either focal or global cerebral ischemia. ${ }^{275-277}$ Inhibition of caspases reduces neuronal injury in both transient focal and global cerebral ischemia. In in vitro experiments, anoxia and oxygen-glucose deprivation (OGD) that mimic the in vivo ischemic injury also result in neuronal apoptosis in primary cultured neurons. ${ }^{258,275,278}$ As a result, apoptotic cell death has been considered as a major cause of neuronal loss during ischemic injury. Consequently, research into the signaling pathways that mediate neuronal apoptosis as well as checkpoint of apoptotic signaling pathways may find new neuroprotective approach for ischemic stroke.

Activation of mTOR prevents apoptosis and promotes cell survival in many cell systems, showing that specific inhibition of mTOR induces apoptosis in a variety of cancer cells, ${ }^{279-293}$ endothelial progenitor cells, ${ }^{294}$ and endothelial cells. ${ }^{295}$ Since inhibition of mTOR increases the vulnerability of tumor cells to apoptosis, ${ }^{72,296-300}$ inhibitors of mTOR have been extensively tested as a chemotherapeutic agents for cancers. ${ }^{301-305}$ In neurons, oxidative stress $\left(\mathrm{H}_{2} \mathrm{O}_{2}\right)$ induces apoptosis in PC12 cells and primary murine neurons by inhibiting mTOR mediated phosphorylation of $\mathrm{p} 70 \mathrm{~S} 6 \mathrm{~K}$ and $4 \mathrm{EBP} 1{ }^{306}$ Serum deprivation induces apoptosis in differentiated R28 rat retinal neuronal cells and induction of $\mathrm{mTOR} / \mathrm{p} 70 \mathrm{~S} 6 \mathrm{~K}$ activation is necessary for insulin to protect retinal neurons against apoptotic cell death induced by serum deprivation since the cytoprotective effects of insulin can be prevented by mTOR inhibitor rapamycin or by a dominant-negative mutant of p70S6K. ${ }^{307}$ However, increased mTOR signaling activation level seems to sensitize neurons to cadmium induced apoptosis and rapamycin and mTOR siRNA markedly downregulates the activation of mTOR targets and prevents cadmium induced neuronal apoptosis. ${ }^{308}$ In addition, we used injury model of OGD in microglia and applied rapamycin to inhibit mTOR signaling prior to OGD. The results indicate that OGD induces a significant injury in microglia revealed by Trypan blue staining, DNA fragmentation and PS externalization. Pharmacological inhibition of mTOR by rapamycin further increases OGD-induced cell injury in microglia, ${ }^{188}$ suggesting that mTOR activation may protect cells against ischemic injury in the CNS.

The anti-apoptotic effect of mTOR has been associated with the modulation of 4EBP1 and p70S6K. Inhibition of mTOR signaling increases binding of 4EBP1 to eukaryotic initiation factor $4 \mathrm{E}$ (eIF4E) leading to translation of $\mathrm{mRNA}$ for pro-apoptotic proteins. ${ }^{309-311}$ Abrogation of mTOR by siRNA interference inhibits phosphorylation of its down stream targets p70S6K and 4EBP1 and induces apoptosis. ${ }^{309}$ OGD-induced apoptosis in astrocytes is enhanced by the combined deletion of p70S6K1 and p70S6K2 genes, as well as by treatment with rapamycin. Further study indicate that astrocytes lacking p70S6K1 and p70S6K2 succumb to apoptosis may due to a defect both in BAD phosphorylation and in the expression of the $\mathrm{Bcl}-2$ and $\mathrm{Bcl}-\mathrm{x}_{\mathrm{L}},{ }^{312}$ suggesting that activation of mTOR downstream target $\mathrm{p} 70 \mathrm{~S} 6 \mathrm{~K}$ 
prevents apoptosis may through promoting anti-apoptotic proteins $\mathrm{Bcl}-2 / \mathrm{Bcl}-\mathrm{x}_{\mathrm{L}}$ expression and inactivating pro-apoptotic protein BAD.

Based on the evidence of the link between mTOR and cell survival, we have investigated the role of mTOR during ischemic brain injury. Our results demonstrate that loss of mTOR activity by its inhibitor rapamycin decreases neuronal survival and increases apoptotic injury in neurons during OGD, an in vitro ischemic model in primary neurons (Fig. 2). In an animal model of focal cerebral ischemia in rats, rapamycin can not only inhibit the activation of mTOR, but also increase the brain infarct size as well as reduce the neurological deficit scores in rats (unpublished data), suggesting that mTOR activation may protect ischemic brain injury and improve functional recovery. Accordingly, some protective agents have been found to protect against ischemic brain injury through activation of mTOR signaling pathway. ${ }^{313,314}$

\section{Future Directions}

Growth factors, amino acids, cellular energy and oxygen supply critically regulate the activation of mTOR signaling cascade. To oversee the cap-dependent protein translation upon activation, mTOR phosphorylates its two major downstream targets, p70S6K and 4EBP1 to promote cell growth, cell proliferation and cell survival. The implication of mTOR signaling pathway in both physiological and pathological process has been extensively investigated with enthusiasm. In addition to its critical role in tumorigenesis, the pathophysiological role of mTOR in the CNS has come to light in recent years. Given the findings that mTOR signaling pathway is involved in the pathogenesis of a variety of neurological diseases, even though the precise underlying mechanisms of mTOR signaling pathway in these diseases are far from clear, targeting mTOR signaling may be a promising strategy against the CNS diseases. Specifically, modulation of cell signaling towards mTOR may initiate neuroprotection and hopefully find a novel therapies for neurodegenerative disorders.

\section{Acknowledgements}

This research was supported by the following grants to Kenneth Maiese: American Diabetes Association, American Heart Association (National), Bugher Foundation Award, Janssen Neuroscience Award, LEARN Foundation Award, Nelson Foundation Award, NIH NIEHS, NIH NIA, NIH NINDS and NIH ARRA.

\section{References}

1. Floyd S, Favre C, Lasorsa FM, Leahy M, Trigiante G, Stroebel P, et al. The insulin-like growth factor-ImTOR signaling pathway induces the mitochondrial pyrimidine nucleotide carrier to promote cell growth. Mol Biol Cell 2007; 18:3545-55.

2. Good DW, George T, Watts BA, 3rd. Nerve growth factor inhibits $\mathrm{Na}^{+} / \mathrm{H}^{+}$exchange and formula absorption through parallel phosphatidylinositol 3-kinase-mTOR and ERK pathways in thick ascending limb. J Biol Chem 2008; 283:26602-11.

3. Han S, Witt RM, Santos TM, Polizzano C, Sabatini BL, Ramesh V. Pam (Protein associated with Myc) functions as an E3 ubiquitin ligase and regulates TSC/ mTOR signaling. Cell Signal 2008; 20:1084-91.

4. Recchia AG, Musti AM, Lanzino M, Panno ML, Turano E, Zumpano R, et al. A cross-talk between the androgen receptor and the epidermal growth factor receptor leads to p38MAPK-dependent activation of $\mathrm{mTOR}$ and cyclinD1 expression in prostate and lung cancer cells. Int J Biochem Cell Biol 2009; 41:603-14.

5. Hosoi H, Dilling MB, Shikata T, Liu LN, Shu L, Ashmun RA, et al. Rapamycin causes poorly reversible inhibition of mTOR and induces p53-independent apoptosis in human rhabdomyosarcoma cells. Cancer Res 1999; 59:886-94.

6. Abraham RT. mTOR as a positive regulator of tumor cell responses to hypoxia. Current topics in microbiology and immunology 2004; 279:299-319.

7. Lopez-Bonet E, Vazquez-Martin A, Perez-Martinez MC, Oliveras-Ferraros C, Perez-Bueno F, Bernado L, et al. Serine 2481-autophosphorylation of mammalian target of rapamycin (mTOR) couples with chromosome condensation and segregation during mitosis: confocal microscopy characterization and immunohistochemical validation of PP-mTOR(Ser2481) as a novel high-contrast mitosis marker in breast cancer core biopsies. Int J Oncol 2010; 36:107-15.

8. Soliman GA, Acosta-Jaquez HA, Dunlop EA, Ekim B, Maj NE, Tee AR, et al. mTOR Ser-2481 autophosphorylation monitors mTORC-specific catalytic activity and clarifies rapamycin mechanism of action. J Biol Chem 2010; 285:7866-79.

9. Hoeffer CA, Klann E. mTOR signaling: at the crossroads of plasticity, memory and disease. Trends Neurosci 2010; 33:67-75.
10. Reynolds THt, Bodine SC, Lawrence JC Jr. Control of Ser2448 phosphorylation in the mammalian target of rapamycin by insulin and skeletal muscle load. J Biol Chem 2002; 277:17657-62.

11. Scott PH, Brunn GJ, Kohn AD, Roth RA, Lawrence JC Jr. Evidence of insulin-stimulated phosphorylation and activation of the mammalian target of rapamycin mediated by a protein kinase B signaling pathway. Proc Natl Acad Sci USA 1998; 95:7772-7.

12. Chen J, Zheng XF, Brown EJ, Schreiber SL. Identification of an $11 \mathrm{kDa}$ FKBP12-rapamycinbinding domain within the $289 \mathrm{kDa}$ FKBP12rapamycin-associated protein and characterization of a critical serine residue. Proc Natl Acad Sci USA 1995; 92:4947-51.

13. Takahara T, Hara K, Yonezawa K, Sorimachi H, Maeda T. Nutrient-dependent multimerization of the mammalian target of rapamycin through the $\mathrm{N}$-terminal HEAT repeat region. J Biol Chem 2006; 281:28605-14.

14. Loewith R, Jacinto E, Wullschleger S, Lorberg A, Crespo JL, Bonenfant D, et al. Two TOR complexes, only one of which is rapamycin sensitive, have distinct roles in cell growth control. Mol Cell 2002; 10:457-68.

15. Sarbassov DD, Ali SM, Sengupta S, Sheen JH, Hsu PP, Bagley AF, et al. Prolonged rapamycin treatment inhibits mTORC2 assembly and Akt/PKB. Mol Cell 2006; 22:159-68.

16. Hara K, Maruki Y, Long X, Yoshino K, Oshiro N, Hidayat $\mathrm{S}$, et al. Raptor, a binding partner of target of rapamycin (TOR), mediates TOR action. Cell 2002; 110:177-89.

17. Kim DH, Sarbassov DD, Ali SM, King JE, Latek RR, Erdjument-Bromage $\mathrm{H}$, et al. mTOR interacts with raptor to form a nutrient-sensitive complex that signals to the cell growth machinery. Cell 2002; 110:163-75.

18. Wang L, Harris TE, Roth RA, Lawrence JC Jr. PRAS40 regulates mTORC1 kinase activity by functioning as a direct inhibitor of substrate binding. J Biol Chem 2007; 282:20036-44.

19. Wang L, Harris TE, Lawrence JC Jr. Regulation of proline-rich Akt substrate of $40 \mathrm{kDa}$ (PRAS40) function by mammalian target of rapamycin complex 1 (mTORC1)-mediated phosphorylation. J Biol Chem 2008; 283:15619-27.
20. Nascimento EB, Snel M, Guigas B, van der Zon GC, Kriek J, Maassen JA, et al. Phosphorylation of PRAS40 on Thr246 by PKB/AKT facilitates efficient phosphorylation of Ser183 by mTORC1. Cell Signal 2010; 22:961-7.

21. Peterson TR, Laplante M, Thoreen CC, Sancak Y, Kang SA, Kuehl WM, et al. DEPTOR is an mTOR inhibitor frequently overexpressed in multiple myeloma cells and required for their survival. Cell 2009; 137:873-86.

22. Masri J, Bernath A, Martin J, Jo OD, Vartanian R, Funk A, et al. mTORC2 activity is elevated in gliomas and promotes growth and cell motility via overexpression of rictor. Cancer Res 2007; 67:11712-20.

23. Sarbassov DD, Guertin DA, Ali SM, Sabatini DM Phosphorylation and regulation of $\mathrm{Akt} / \mathrm{PKB}$ by the rictor-mTOR complex. Science 2005; 307:1098-101.

24. Frias MA, Thoreen CC, Jaffe JD, Schroder W, Sculley $\mathrm{T}$, Carr SA, et al. mSin 1 is necessary for Akt/PKB phosphorylation and its isoforms define three distinct mTORC2s. Curr Biol 2006; 16:1865-70.

25. Jacinto E, Facchinetti V, Liu D, Soto N, Wei S, Jung SY, et al. SIN1/MIP1 maintains rictor-mTOR complex integrity and regulates Akt phosphorylation and substrate specificity. Cell 2006; 127:125-37.

26. Guertin DA, Stevens DM, Thoreen CC, Burds AA, Kalaany NY, Moffat J, et al. Ablation in mice of the mTORC components raptor, rictor or mLST8 reveals that mTORC2 is required for signaling to AktFOXO and PKCalpha, but not S6K1. Dev Cell 2006; 11:859-71.

27. Pearce LR, Huang X, Boudeau J, Pawlowski R, Wullschleger S, Deak M, et al. Identification of Protor as a novel Rictor-binding component of mTOR complex-2. Biochem J 2007; 405:513-22.

28. Inoki K, Li Y, Zhu T, Wu J, Guan KL. TSC2 is phosphorylated and inhibited by Akt and suppresses mTOR signalling. Nat Cell Biol 2002; 4:648-57.

29. Sato T, Nakashima A, Guo L, Tamanoi F. Specific activation of mTORC1 by Rheb G-protein in vitro involves enhanced recruitment of its substrate protein. J Biol Chem 2009; 284:12783-91.

30. Cai SL, Tee AR, Short JD, Bergeron JM, Kim J, Shen $\mathrm{J}$, et al. Activity of TSC2 is inhibited by AKT-mediated phosphorylation and membrane partitioning. J Cell Biol 2006; 173:279-89. 
31. Ma L, Chen Z, Erdjument-Bromage H, Tempst P, Pandolfi PP. Phosphorylation and functional inactivation of TSC2 by Erk implications for tuberous sclerosis and cancer pathogenesis. Cell 2005; 121:179-93.

32. Nellist M, Burgers PC, van den Ouweland AM, Halley DJ, Luider TM. Phosphorylation and binding partner analysis of the TSC1-TSC2 complex. Biochem Biophys Res Commun 2005; 333:818-26.

33. Bai X, Ma D, Liu A, Shen X, Wang QJ, Liu Y, et al. Rheb activates mTOR by antagonizing its endogenous inhibitor, FKBP38. Science 2007; 318:977-80.

34. Chong ZZ, Kang JQ, Maiese K. Erythropoietin is a novel vascular protectant through activation of Akt1 and mitochondrial modulation of cysteine proteases. Circulation 2002; 106:2973-9.

35. Chong ZZ, Li F, Maiese K. Activating Akt and the brain's resources to drive cellular survival and prevent inflammatory injury. Histol Histopathol 2005; 20:299-315.

36. Chong ZZ, Li F, Maiese K. Group I Metabotropic Receptor Neuroprotection Requires Akt and Its Substrates that Govern FOXO3a, Bim and betaCatenin During Oxidative Stress. Curr Neurovasc Res 2006; 3:107-17.

37. Kang JQ, Chong ZZ, Maiese K. Akt1 protects against inflammatory microglial activation through maintenance of membrane asymmetry and modulation of cysteine protease activity. J Neurosci Res 2003; 74:37-51.

38. Li F, Chong ZZ, Maiese K. Microglial integrity is maintained by erythropoietin through integration of Akt and its substrates of glycogen synthase kinase3beta, beta-catenin and nuclear factorkappaB. Curr Neurovasc Res 2006; 3:187-201.

39. Maiese K, Chong ZZ, Hou J, Shang YC. The vitamin nicotinamide: translating nutrition into clinical care. Molecules 2009; 14:3446-85.

40. Chong ZZ, Li F, Maiese K. Stress in the brain: novel cellular mechanisms of injury linked to Alzheimer's disease. Brain Res Brain Res Rev 2005; 49:1-21.

41. Stephens L, Anderson K, Stokoe D, ErdjumentBromage H, Painter GF, Holmes AB, et al. Protein kinase B kinases that mediate phosphatidylinositol 3,4,5-trisphosphate-dependent activation of protein kinase B. Science 1998; 279:710-4.

42. Potter CJ, Pedraza LG, Xu T. Akt regulates growth by directly phosphorylating Tsc2. Nat Cell Biol 2002; 4:658-65.

43. Fonseca BD, Smith EM, Lee VH, MacKintosh C, Proud CG. PRAS40 is a target for mammalian target of rapamycin complex 1 and is required for signaling downstream of this complex. J Biol Chem 2007; 282:24514-24.

44. Oshiro N, Yoshino K, Hidayat S, Tokunaga C, Hara K, Eguchi $\mathrm{S}$, et al. Dissociation of raptor from $\mathrm{mTOR}$ is a mechanism of rapamycin-induced inhibition of mTOR function. Genes Cells 2004; 9:359-66.

45. Sancak Y, Thoreen CC, Peterson TR, Lindquist RA, Kang SA, Spooner E, et al. PRAS40 is an insulinregulated inhibitor of the $\mathrm{mTORC} 1$ protein kinase. Mol Cell 2007; 25:903-15.

46. Vander Haar E, Lee SI, Bandhakavi S, Griffin TJ, Kim $\mathrm{DH}$. Insulin signalling to mTOR mediated by the Akt/ PKB substrate PRAS40. Nat Cell Biol 2007; 9:316-23.

47. Harrington LS, Findlay GM, Gray A, Tolkacheva T, Wigfield S, Rebholz H, et al. The TSC1-2 tumor suppressor controls insulin-PI3K signaling via regulation of IRS proteins. J Cell Biol 2004; 166:213-23.

48. Carriere A, Cargnello M, Julien LA, Gao H, Bonneil E, Thibault P, et al. Oncogenic MAPK signaling stimulates mTORC1 activity by promoting RSK-mediated raptor phosphorylation. Curr Biol 2008; 18:1269-77.

49. Foster KG, Acosta-Jaquez HA, Romeo Y, Ekim B, Soliman GA, Carriere A, et al. Regulation of mTOR complex 1 (mTORC1) by raptor Ser863 and multisite phosphorylation. J Biol Chem 2010; 285:80-94.
50. Wang L, Lawrence JC Jr, Sturgill TW, Harris TE. Mammalian target of rapamycin complex 1 (mTORC1) activity is associated with phosphorylation of raptor by mTOR. J Biol Chem 2009; 284:14693-7.

51. Dennis PB, Thomas G. Quick guide: target of rapamycin. Curr Biol 2002; 12:269.

52. Sofer A, Lei K, Johannessen CM, Ellisen LW. Regulation of mTOR and cell growth in response to energy stress by REDD1. Mol Cell Biol 2005; 25:5834-45.

53. Inoki $\mathrm{K}$, Zhu T, Guan KL. TSC2 mediates cellular energy response to control cell growth and survival. Cell 2003; 115:577-90.

54. Kahn BB, Alquier T, Carling D, Hardie DG. AMPactivated protein kinase: ancient energy gauge provides clues to modern understanding of metabolism. Cell Metab 2005; 1:15-25.

55. Hahn-Windgassen A, Nogueira V, Chen CC, Skeen JE, Sonenberg N, Hay N. Akt activates the mammalian target of rapamycin by regulating cellular ATP level and AMPK activity. J Biol Chem 2005; 280:32081-9.

56. Gwinn DM, Shackelford DB, Egan DF, Mihaylova MM, Mery A, Vasquez DS, et al. AMPK phosphorylation of raptor mediates a metabolic checkpoint. Mol Cell 2008; 30:214-26.

57. Shaw RJ, Kosmatka M, Bardeesy N, Hurley RL, Witters LA, DePinho RA, et al. The tumor suppressor LKB1 kinase directly activates AMP-activated kinase and regulates apoptosis in response to energy stress. Proc Natl Acad Sci USA 2004; 101:3329-35.

58. Budanov AV, Karin M. p53 target genes sestrin 1 and sestrin2 connect genotoxic stress and mTOR signaling. Cell 2008; 134:451-60.

59. Liu L, Cash TP, Jones RG, Keith B, Thompson CB, Simon MC. Hypoxia-induced energy stress regulates mRNA translation and cell growth. Mol Cell 2006; 21:521-31.

60. Brugarolas J, Lei K, Hurley RL, Manning BD, Reiling $\mathrm{JH}$, Hafen E, et al. Regulation of mTOR function in response to hypoxia by REDD1 and the TSC1/ TSC2 tumor suppressor complex. Genes Dev 2004; 18:2893-904

61. DeYoung MP, Horak P, Sofer A, Sgroi D, Ellisen LW. Hypoxia regulates TSC1/2-mTOR signaling and tumor suppression through REDD1-mediated 14-3-3 shuttling. Genes Dev 2008; 22:239-51.

62. Favier FB, Costes F, Defour A, Bonnefoy R, Lefai E, Bauge $S$, et al. Downregulation of Akt/mammalian target of rapamycin pathway in skeletal muscle is associated with increased REDD1 expression in response to chronic hypoxia. Am J Physiol Regul Integr Comp Physiol 2010; 298:1659-66.

63. Schneider A, Younis RH, Gutkind JS. Hypoxiainduced energy stress inhibits the mTOR pathway by activating an AMPK/REDD1 signaling axis in head and neck squamous cell carcinoma. Neoplasia 2008; 10:1295-302

64. Jin HO, An S, Lee HC, Woo SH, Seo SK, Choe TB, et al. Hypoxic condition- and high cell density-induced expression of Redd 1 is regulated by activation of hypoxia-inducible factor-1alpha and Sp1 through the phosphatidylinositol-3-kinase/Akt signaling pathway. Cell Signal 2007; 19:1393-403.

65. Regazzetti C, Bost F, Le Marchand-Brustel Y, Tanti JF, Giorgetti-Peraldi S. Insulin induces REDD1 expression through hypoxia-inducible factor 1 activation in adipocytes. J Biol Chem 2010; 285:5157-64.

66. Beugnet A, Tee AR, Taylor PM, Proud CG. Regulation of targets of mTOR (mammalian target of rapamycin) signalling by intracellular amino acid availability. Biochem J 2003; 372:555-66.

67. Dreyer HC, Drummond MJ, Pennings B, Fujita S, Glynn EL, Chinkes DL, et al. Leucine-enriched essential amino acid and carbohydrate ingestion following resistance exercise enhances mTOR signaling and protein synthesis in human muscle. Am J Physio Endocrinol Metab 2008; 294:392-400.
68. Long X, Ortiz-Vega S, Lin Y, Avruch J. Rheb binding to mammalian target of rapamycin (mTOR) is regulated by amino acid sufficiency. J Biol Chem 2005; 280:23433-6.

69. Peyrollier K, Hajduch E, Blair AS, Hyde R, Hundal HS. L-leucine availability regulates phosphatidylinositol-3-kinase, p70 S6 kinase and glycogen synthase kinase-3 activity in L6 muscle cells: evidence for the involvement of the mammalian target of rapamycin (mTOR) pathway in the L-leucine-induced upregulation of system A amino acid transport. Biochem J 2000; 350:361-8.

70. Sato T, Nakashima A, Guo L, Coffman K, Tamanoi F. Single amino-acid changes that confer constitutive activation of $\mathrm{mTOR}$ are discovered in human cancer. Oncogene 2010; 29:2746-52.

71. Tremblay F, Marette A. Amino acid and insulin signaling via the $\mathrm{mTOR} / \mathrm{p} 70 \mathrm{~S} 6$ kinase pathway. A negative feedback mechanism leading to insulin resistance in skeletal muscle cells. J Biol Chem 2001; 276:38052-60.

72. Zhang YJ, Tian XQ, Sun DF, Zhao SL, Xiong H, Fang JY. Combined inhibition of MEK and mTOR signaling inhibits initiation and progression of colorectal cancer. Cancer Invest 2009; 27:273-85.

73. Nicklin P, Bergman P, Zhang B, Triantafellow E, Wang $\mathrm{H}$, Nyfeler B, et al. Bidirectional transport of amino acids regulates mTOR and autophagy. Cell 2009; 136:521-34.

74. Smith EM, Finn SG, Tee AR, Browne GJ, Proud CG. The tuberous sclerosis protein TSC2 is not required for the regulation of the mammalian target of rapamycin by amino acids and certain cellular stresses. J Biol Chem 2005; 280:18717-27.

75. Heublein S, Kazi S, Ogmundsdottir MH, Attwood EV, Kala S, Boyd CA, et al. Proton-assisted aminoacid transporters are conserved regulators of proliferation and amino-acid-dependent mTORC1 activation. Oncogene 2010; 29:4068-79.

76. Sancak Y, Peterson TR, Shaul YD, Lindquist RA, Thoreen CC, Bar-Peled L, et al. The Rag GTPases bind raptor and mediate amino acid signaling to mTORC1. Science 2008; 320:1496-501.

77. Li L, Kim E, Yuan H, Inoki K, Goraksha-Hicks P, Schiesher RL, et al. Regulation of mTORC1 by the Rab and Arf GTPases. J Biol Chem 2010; 285:197059.

78. Sancak Y, Bar-Peled L, Zoncu R, Markhard AL Nada S, Sabatini DM. Ragulator-Rag complex targets mTORC1 to the lysosomal surface and is necessary for its activation by amino acids. Cell 2010; 141:290-303.

79. Huang J, Dibble CC, Matsuzaki M, Manning BD. The TSC1-TSC2 complex is required for proper activation of mTOR complex 2. Mol Cell Biol 2008; 28:4104-15.

80. Huang J, Wu S, Wu CL, Manning BD. Signaling events downstream of mammalian target of rapamycin complex 2 are attenuated in cells and tumors deficient for the tuberous sclerosis complex tumor suppressors. Cancer Res 2009; 69:6107-14.

81. Dibble CC, Asara JM, Manning BD. Characterization of Rictor phosphorylation sites reveals direct regulation of mTOR complex 2 by S6K1. Mol Cell Biol 2009; 29:5657-70.

82. Treins C, Warne PH, Magnuson MA, Pende M, Downward J. Rictor is a novel target of p70 S6 kinase-1. Oncogene 2010; 29:1003-16.

83. Julien LA, Carriere A, Moreau J, Roux PP. mTORC1activated S6K1 phosphorylates Rictor on threonine 1135 and regulates mTORC2 signaling. Mol Cell Biol 2010; 30:908-21.

84. Harwood FC, Shu L, Houghton PJ. mTORC1 signaling can regulate growth factor activation of $\mathrm{p} 44 / 42$ mitogen-activated protein kinases through protein phosphatase 2A. J Biol Chem 2008; 283:2575-85.

85. Hosokawa N, Hara T, Kaizuka T, Kishi C, Takamura A, Miura Y, et al. Nutrient-dependent mTORC1 association with the ULK1-Atg13-FIP200 complex required for autophagy. Mol Biol Cell 2009; 20:1981-91. 
86. Grozinsky-Glasberg S, Franchi G, Teng M, Leontiou CA, Ribeiro de Oliveira A Jr, Dalino P, et al. Octreotide and the mTOR inhibitor RAD001 (everolimus) block proliferation and interact with the Akt-mTOR-p70S6K pathway in a neuro-endocrine tumour cell Line. Neuroendocrinology 2008; 87:168-81.

87. Pearson RB, Dennis PB, Han JW, Williamson NA, Kozma SC, Wettenhall RE, et al. The principal target of rapamycin-induced $\mathrm{p} 70 \mathrm{~s} 6 \mathrm{k}$ inactivation is a novel phosphorylation site within a conserved hydrophobic domain. EMBO J 1995; 14:5279-87.

88. Holz MK, Ballif BA, Gygi SP, Blenis J. mTOR and S6K1 mediate assembly of the translation preinitiation complex through dynamic protein interchange and ordered phosphorylation events. Cell 2005; 123:569-80.

89. Fingar DC, Richardson CJ, Tee AR, Cheatham L, Tsou C, Blenis J. mTOR controls cell cycle progression through its cell growth effectors S6K1 and 4E-BP1/ eukaryotic translation initiation factor $4 \mathrm{E}$. Mol Cell Biol 2004; 24:200-16.

90. Gingras AC, Kennedy SG, O’Leary MA, Sonenberg N, Hay N. 4E-BP1, a repressor of mRNA translation, is phosphorylated and inactivated by the $\mathrm{Akt}(\mathrm{PKB})$ signaling pathway. Genes Dev 1998; 12:502-13.

91. Magagnin $\mathrm{MG}$, van den Beucken $\mathrm{T}$, Sergeant $\mathrm{K}$, Lambin P, Koritzinsky M, Devreese B, et al. The mTOR target 4E-BP1 contributes to differential protein expression during normoxia and hypoxia through changes in mRNA translation efficiency. Proteomics 2008; 8:1019-28.

92. Jacinto E, Loewith R, Schmidt A, Lin S, Ruegg MA, Hall A, et al. Mammalian TOR complex 2 controls the actin cytoskeleton and is rapamycin insensitive. Nat Cell Biol 2004; 6:1122-8.

93. Barilli A, Visigalli R, Sala R, Gazzola GC, Parolari A, Tremoli E, et al. In human endothelial cells rapamycin causes mTORC2 inhibition and impairs cell viability and function. Cardiovasc Res 2008; 78:563-71.

94. Carayol N, Vakana E, Sassano A, Kaur S, Goussetis DJ, Glaser H, et al. Critical roles for mTORC2- and rapamycin-insensitive mTORC1-complexes in growth and survival of BCR-ABL-expressing leukemic cells. Proc Natl Acad Sci USA 2010; 107:12469-74

95. Dada S, Demartines N, Dormond O. mTORC2 regulates PGE2-mediated endothelial cell survival and migration. Biochem Biophys Res Commun 2008; 372:875-9.

96. Rosner M, Fuchs C, Siegel N, Valli A, Hengstschlager M. Functional interaction of mammalian target of rapamycin complexes in regulating mammalian cell size and cell cycle. Hum Mol Genet 2009; 18:3298-310.

97. Rosner M, Hengstschlager M. Cytoplasmic and nuclear distribution of the protein complexes mTORC1 and mTORC2: rapamycin triggers dephosphorylation and delocalization of the mTORC2 components rictor and sin1. Hum Mol Genet 2008; 17:2934-48.

98. Roulin D, Cerantola Y, Dormond-Meuwly A, Demartines N, Dormond O. Targeting mTORC2 inhibits colon cancer cell proliferation in vitro and tumor formation in vivo. Mol Cancer 2010; 9:57.

99. Sarbassov DD, Ali SM, Kim DH, Guertin DA, Latek $\mathrm{RR}$, Erdjument-Bromage $\mathrm{H}$, et al. Rictor, a novel binding partner of $\mathrm{mTOR}$, defines a rapamycin-insensitive and raptor-independent pathway that regulates the cytoskeleton. Curr Biol 2004; 14:1296-302.

100. Hernandez-Negrete I, Carretero-Ortega J, Rosenfeldt H, Hernandez-Garcia R, Calderon-Salinas JV, ReyesCruz G, et al. P-Rex1 links mammalian target of rapamycin signaling to Rac activation and cell migration. J Biol Chem 2007; 282:23708-15.

101. Kelleher RJ, 3rd, Govindarajan A, Jung HY, Kang H, Tonegawa S. Translational control by MAPK signaling in long-term synaptic plasticity and memory. Cell 2004; 116:467-79

102. Tang SJ, Reis G, Kang H, Gingras AC, Sonenberg N, Schuman EM. A rapamycin-sensitive signaling pathway contributes to long-term synaptic plasticity in the hippocampus. Proc Natl Acad Sci USA 2002; 99:467-72.
103. Slipczuk L, Bekinschtein P, Katche C, Cammarota M Izquierdo I, Medina JH. BDNF activates mTOR to regulate GluR1 expression required for memory formation. PLoS One 2009; 4:6007.

104. Sui L, Wang J, Li BM. Role of the phosphoinositide3-kinase-Akt-mammalian target of the rapamycin signaling pathway in long-term potentiation and trace fea conditioning memory in rat medial prefrontal cortex. Learning \& memory (Cold Spring Harbor, NY) 2008 15:762-76.

105. Blundell J, Kouser M, Powell CM. Systemic inhibition of mammalian target of rapamycin inhibits fea memory reconsolidation. Neurobiology of learning and memory 2008; 90:28-35.

106. Parsons RG, Gafford GM, Helmstetter FJ. Translationa control via the mammalian target of rapamycin pathway is critical for the formation and stability of long term fear memory in amygdala neurons. J Neurosci 2006; 26:12977-83

107. Yang PC, Yang $\mathrm{CH}$, Huang CC, Hsu KS. Phosphatidylinositol-3-kinase activation is required for stress protocol-induced modification of hippocampal synaptic plasticity. J Biol Chem 2008; 283:2631-43.

108. Cota D, Proulx K, Smith KA, Kozma SC, Thomas G, Woods SC, et al. Hypothalamic mTOR signaling regulates food intake. Science 2006; 312:927-30.

109. Roa J, Garcia-Galiano D, Varela L, Sanchez-Garrido MA, Pineda R, Castellano JM, et al. The mammalian target of rapamycin as novel central regulator of puberty onset via modulation of hypothalamic Kiss system. Endocrinology 2009; 150:5016-26.

110. d'Anglemont de Tassigny X, Fagg LA, Dixon JP, Day K, Leitch HG, Hendrick AG, et al. Hypogonadotropic hypogonadism in mice lacking a functional Kiss 1 gene. Proc Natl Acad Sci USA 2007; 104:10714-9.

111. Smith JT. Sex steroid control of hypothalamic Kiss 1 expression in sheep and rodents: comparative aspects. Peptides 2009; 30:94-102.

112. Bisby MA, Tetzlaff W. Changes in cytoskeletal protein synthesis following axon injury and during axon regeneration. Mol Neurobiol 1992; 6:107-23.

113. Gao Y, Deng K, Hou J, Bryson JB, Barco A, Nikulin E, et al. Activated CREB is sufficient to overcome inhibitors in myelin and promote spinal axon regeneration in vivo. Neuron 2004; 44:609-21.

114. Gumy LF, Tan CL, Fawcett JW. The role of local protein synthesis and degradation in axon regeneration. Exp Neurol 2010; 223:28-37.

115. Park KK, Liu K, Hu Y, Smith PD, Wang C, Cai B, et al. Promoting axon regeneration in the adult CNS by modulation of the PTEN/mTOR pathway. Science 2008; 322:963-6

116. Verma P, Chierzi S, Codd AM, Campbell DS, Meyer RL, Holt CE, et al. Axonal protein synthesis and degradation are necessary for efficient growth cone regeneration. J Neurosci 2005; 25:331-42.

117. Maehama T, Dixon JE. The tumor suppressor, PTEN/ MMAC1, dephosphorylates the lipid second messenger, phosphatidylinositol-3,4,5-trisphosphate. J Biol Chem 1998; 273:13375-8

118. Choi Y, Zhang J, Murga C, Yu H, Koller E, Monia BP, et al. PTEN, but not SHIP and SHIP2, suppresses the PI3K/Akt pathway and induces growth inhibition and apoptosis of myeloma cells. Oncogene 2002; 21:5289-300

119. Paez J, Sellers WR. PI3K/PTEN/AKT pathway. A critical mediator of oncogenic signaling. Cancer treatment and research 2003; 115:145-67.

120. Liu K, Lu Y, Lee JK, Samara R, Willenberg R, SearsKraxberger I, et al. PTEN deletion enhances the regenerative ability of adult corticospinal neurons. Nat Neurosci 2010; 13:1075-81.

121. Codeluppi S, Svensson CI, Hefferan MP, Valencia F, Silldorff MD, Oshiro M, et al. The Rheb-mTOR pathway is upregulated in reactive astrocytes of the injured spinal cord. J Neurosci 2009; 29:1093-104.
122. Anders JJ, Hurlock JA. Transplanted glial scar impedes olfactory bulb reinnervation. Exp Neurol 1996; 142:144-50.

123. Reier PJ, Houle JD. The glial scar: its bearing on axonal elongation and transplantation approaches to CNS repair. Adv Neurol 1988; 47:87-138.

124. Rhodes KE, Moon LD, Fawcett JW. Inhibiting cell proliferation during formation of the glial scar: effects on axon regeneration in the CNS. Neuroscience 2003; 120:41-56.

125. Ribotta MG, Menet V, Privat A. Glial scar and axonal regeneration in the CNS: lessons from GFAP and vimentin transgenic mice. Acta Neurochir Suppl 2004; 89:87-92.

126. Wanner IB, Deik A, Torres M, Rosendahl A, Neary JT, Lemmon VP, et al. A new in vitro model of the glial scar inhibits axon growth. Glia 2008; 56:1691-709.

127. Abe N, Borson SH, Gambello MJ, Wang F, Cavalli V. Mammalian target of rapamycin (mTOR) activation increases axonal growth capacity of injured peripheral nerves. J Biol Chem 2010; 285:28034-43.

128. Chong ZZ, Li F, Maiese K. Employing new cellular therapeutic targets for Alzheimer's disease: a change for the better? Curr Neurovasc Res 2005; 2:55-72.

129. Maiese K, Chong ZZ, Hou J, Shang YC. New strategies for Alzheimer's disease and cognitive impairment. Oxid Med Cell Longev 2009; 2:279-89.

130. Maiese K. The dynamics of cellular injury: transformation into neuronal and vascular protection. Histo Histopathol 2001; 16:633-44.

131. Maiese K, Chong ZZ, Li F. Driving cellular plasticity and survival through the signal transduction pathways of metabotropic glutamate receptors. Curr Neurovasc Res 2005; 2:425-46.

132. Maiese K, Chong ZZ, Shang YC. Raves and risks for erythropoietin. Cytokine Growth Factor Rev 2008; 19:145-55

133. Erol A. Unraveling the Molecular Mechanisms Behind the Metabolic Basis of Sporadic Alzheimer's Disease. J Alzheimers Dis 2009.

134. Chong ZZ, Li F, Maiese K. Erythropoietin requires NFkappaB and its nuclear translocation to prevent early and late apoptotic neuronal injury during betaamyloid toxicity. Curr Neurovasc Res 2005; 2:387-99.

135. Chong ZZ, Li F, Maiese K. Cellular demise and inflam matory microglial activation during beta-amyloid toxicity are governed by Wnt 1 and canonical signaling pathways. Cell Signal 2007; 19:1150-62.

136. Lu J, Wu DM, Zheng YL, Sun DX, Hu B, Shan Q, et al. Trace amounts of copper exacerbate beta amyloidinduced neurotoxicity in the cholesterol-fed mice through TNF-mediated inflammatory pathway. Brain Behav Immun 2009; 23:193-203

137. Majd S, Rastegar K, Zarifkar A, Takhshid MA. Fibrillar beta-amyloid (Abeta) (1-42) elevates extracellular Abeta in cultured hippocampal neurons of adult rats. Brain Res 2007; 1185:321-7.

138. Majd S, Zarifkar A, Rastegar K, Takhshid MA. Different fibrillar Abeta 1-42 concentrations induce adult hippocampal neurons to reenter various phases of the cell cycle. Brain Res 2008; 1218:224-9.

139. Chong ZZ, Li F, Maiese K. Oxidative stress in the brain: Novel cellular targets that govern survival during neurodegenerative disease. Prog Neurobiol 2005; 75:207-46.

140. Guglielmotto M, Tamagno E, Danni O. Oxidative stress and hypoxia contribute to Alzheimer's disease pathogenesis: two sides of the same coin. Scientific World Journal 2009; 9:781-91.

141. Liu T, Jin H, Sun QR, Xu JH, Hu HT. The neuroprotective effects of tanshinone IIA on beta-amyloid-induced toxicity in rat cortical neurons. Neuropharmacology 2010; 59:595-604.

142. Maiese K, Chong ZZ, Hou J, Shang YC. Erythropoietin and oxidative stress. Curr Neurovasc Res 2008; 5:125-42. 
143. Maiese K, Chong ZZ, Shang YC. OutFOXOing disease and disability: the therapeutic potential of targeting FoxO proteins. Trends Mol Med 2008; 14:219-27.

144. Su SY, Cheng CY, Tsai TH, Hsiang CY, Ho TY, Hsieh CL. Paeonol attenuates HO-induced NFkappaBassociated amyloid precursor protein expression. Am J Chin Med 2010; 38:1171-92.

145. Maiese K, Hou J, Chong ZZ, Shang YC. A fork in the path: Developing therapeutic inroads with FoxO proteins. Oxid Med Cell Longev 2009; 2:119-29.

146. Maiese K, Li F, Chong ZZ, Shang YC. The Wnt signaling pathway: Aging gracefully as a protectionist? Pharmacol Ther 2008; 118:58-81.

147. Maiese K, Shang YC, Chong ZZ, Hou J. Diabetes mellitus: channeling care through cellular discovery. Curr Neurovasc Res 2010; 7:59-64.

148. Maiese K, Chong ZZ, Li F, Shang YC. Erythropoietin: elucidating new cellular targets that broaden therapeutic strategies. Prog Neurobiol 2008; 85:194-213.

149. Regulska M, Leskiewicz M, Budziszewska B, Kutner A, Jantas D, Basta-Kaim A, et al. Inhibitory effects of 1,25-dihydroxyvitamin $\mathrm{D}(3)$ and its low-calcemic analogues on staurosporine-induced apoptosis. Pharmacol Rep 2007; 59:393-401

150. Chlopicki S, Swies J, Mogielnicki A, Buczko W, Bartus M, Lomnicka M, et al. 1-Methylnicotinamide (MNA), a primary metabolite of nicotinamide, exerts antithrombotic activity mediated by a cyclooxygenase- $2 /$ prostacyclin pathway. Br J Pharmacol 2007; 152:230-9.

151. Chong ZZ, Lin SH, Maiese K. Nicotinamide Modulates Mitochondrial Membrane Potential and Cysteine Protease Activity during Cerebral Vascular Endothelial Cell Injury. J Vasc Res 2002; 39:131-47.

152. Feng Y, Paul IA, LeBlanc MH. Nicotinamide reduces hypoxic ischemic brain injury in the newborn rat. Brain Res Bull 2006; 69:117-22.

153. Hara N, Yamada K, Shibata T, Osago H, Hashimoto T, Tsuchiya M. Elevation of cellular NAD levels by nicotinic acid and involvement of nicotinic acid phosphoribosyltransferase in human cells. J Biol Chem 2007; 282:24574-82.

154. Ieraci A, Herrera DG. Nicotinamide Protects against Ethanol-Induced Apoptotic Neurodegeneration in the Developing Mouse Brain. PLoS Med 2006; 3:101.

155. Lin SH, Vincent A, Shaw T, Maynard KI, Maiese K. Prevention of nitric oxide-induced neuronal injury through the modulation of independent pathways of programmed cell death. J Cereb Blood Flow Metab 2000; 20:1380-91.

156. Maiese K, Chong ZZ. Nicotinamide: necessary nutrient emerges as a novel cytoprotectant for the brain. Trends Pharmacol Sci 2003; 24:228-32.

157. Chong ZZ, Li F, Maiese K. Attempted Cell Cycle Induction in Post-Mitotic Neurons Occurs in Early and Late Apoptotic Programs Through Rb, E2F1 and Caspase 3. Curr Neurovasc Res 2006; 3:25-39.

158. De Felice FG, Velasco PT, Lambert MP, Viola K, Fernandez SJ, Ferreira ST, et al. Abeta oligomers induce neuronal oxidative stress through an $\mathrm{N}$-methyl$\mathrm{D}$-aspartate receptor-dependent mechanism that is blocked by the Alzheimer drug memantine. J Biol Chem 2007; 282:11590-601.

159. Lin SH, Maiese K. The metabotropic glutamate receptor system protects against ischemic free radical programmed cell death in rat brain endothelial cells. J Cereb Blood Flow Metab 2001; 21:262-75.

160. Lee SJ, Cho KS, Koh JY. Oxidative injury triggers autophagy in astrocytes: the role of endogenous zinc. Glia 2009; 57:1351-61

161. He Z, Lu Q, Xu X, Huang L, Chen J, Guo L. DDPH ameliorated oxygen and glucose deprivation-induced injury in rat hippocampal neurons via interrupting $\mathrm{Ca}^{2+}$ overload and glutamate release. Eur J Pharmacol 2009; 603:50-5

162. Maiese K, Chong ZZ, Shang YC, Hou J. Clever cancer strategies with FoxO transcription factors. Cell Cycle 2008; 7:3829-39.
163. Maiese K, Chong ZZ, Shang YC, Hou J. Therapeutic promise and principles: Metabotropic glutamate receptors. Oxid Med Cell Longev 2008; 1:1-14.

164. Plecita-Hlavata L, Lessard M, Santorova J, Bewersdorf J, Jezek P. Mitochondrial oxidative phosphorylation and energetic status are reflected by morphology of mitochondrial network in INS-1E and HEP-G2 cells viewed by $4 \mathrm{Pi}$ microscopy. Biochim Biophys Acta 2008; 1777:834-46.

165. Hou J, Chong ZZ, Shang YC, Maiese K. FoxO3a governs early and late apoptotic endothelial programs during elevated glucose through mitochondrial and caspase signaling. Mol Cell Endocrinol 2010; 321:194-206.

166. Hou J, Chong ZZ, Shang YC, Maiese K. Early apoptotic vascular signaling is determined by Sirt 1 through nuclear shuttling, forkhead trafficking, bad and mitochondrial caspase activation. Curr Neurovasc Res 2010; 7:95-112.

167. Kashihara N, Haruna Y, Kondeti VK, Kanwar YS Oxidative stress in diabetic nephropathy. Curr Med Chem 2010; 17:4256-69.

168. Shaik NA, Shaik JP, Ali S, Imran A, Rao DK. Increased frequency of micronuclei in diabetes mellitus patients using pioglitazone and glimepiride in combination. Food Chem Toxicol 2010; 48:3432-5.

169. Soo ET, Ng YK, Bay BH, Yip GW. Heat shock proteins and neurodegenerative disorders. ScientificWorldJournal 2008; 8:270-4.

170. van den Boogaard M, Ramakers BP, van Alfen N, van der Werf SP, Fick WF, Hoedemaekers CW, et al. Endotoxemia-induced inflammation and the effect on the human brain. Crit Care 2010; 14:81.

171. Walden AP, Young JD, Sharples E. Bench to bedside: A role for erythropoietin in sepsis. Crit Care 2010; 14:227.

172. Nagley P, Higgins GC, Atkin JD, Beart PM. Multifaceted deaths orchestrated by mitochondria in neurones. Biochim Biophys Acta 2009.

173. Chauhan NB, Gatto R. Synergistic benefits of erythropoietin and simvastatin after traumatic brain injury. Brain Res 2010; 1360:177-92.

174. Hong Y, Yan W, Chen S, Sun CR, Zhang JM. The role of Nrf2 signaling in the regulation of antioxidants and detoxifying enzymes after traumatic brain injury in rats and mice. Acta Pharmacol Sin 2010; 31:1421-30.

175. Velly L, Pellegrini L, Guillet B, Bruder N, Pisano P. Erythropoietin $2^{\text {nd }}$ cerebral protection after acute injuries: a double-edged sword? Pharmacol Ther 2010; 128:445-59.

176. Harris SE, Fox H, Wright AF, Hayward C, Starr JM, Whalley LJ, et al. A genetic association analysis of cognitive ability and cognitive ageing using 325 markers for 109 genes associated with oxidative stress or cognition. BMC Genet 2007; 8:43.

177. Leuner K, Hauptmann S, Abdel-Kader R, Scherping I, Keil U, Strosznajder JB, et al. Mitochondrial dysfunction: the first domino in brain aging and Alzheimer's disease? Antioxid Redox Signal 2007; 9:1659-75.

178. Okouchi M, Ekshyyan O, Maracine M, Aw TY. Neuronal apoptosis in neurodegeneration. Antioxid Redox Signal 2007; 9:1059-96.

179. Shang YC, Chong ZZ, Hou J, Maiese K. The forkhead transcription factor FoxO3a controls microglial inflammatory activation and eventual apoptotic injury through caspase 3. Curr Neurovasc Res 2009; 6:20-31.

180. Shang YC, Chong ZZ, Hou J, Maiese K. FoxO3a governs early microglial proliferation and employs mitochondrial depolarization with caspase 3,8 and 9 cleavage during oxidant induced apoptosis. Curr Neurovasc Res 2009; 6:223-38.

181. Shang YC, Chong ZZ, Hou J, Maiese K. Wnt1, FoxO3a and NFkappaB oversee microglial integrity and activation during oxidant stress. Cell Signal 2010; 22:1317-29.

182. Maiese K, Hou J, Chong ZZ, Shang YC. Erythropoietin, forkhead proteins and oxidative injury: biomarkers and biology. ScientificWorldJournal 2009; 9:1072-104.
183. Maiese K, Li F, Chong ZZ. New avenues of exploration for erythropoietin. Jama 2005; 293:90-5.

184. Ogino A, Takemura G, Kawasaki M, Tsujimoto A, Kanamori H, Li L, et al. Erythropoietin receptor signaling mitigates renal dysfunction-associated heart failure by mechanisms unrelated to relief of anemia. J Am Coll Cardiol 2010; 56:1949-58.

185. Ponikowski P, Jankowska EA. EPO's rescue mission in acute myocardial infarction: still more hopes than evidence. Eur Heart J 2010; 31:2577-9.

186. Taniguchi N, Nakamura T, Sawada T, Matsubara K, Furukawa K, Hadase M, et al. Erythropoietin prevention trial of coronary restenosis and cardiac remodeling after ST-elevated acute myocardial infarction (EPOCAMI): a pilot, randomized, placebo-controlled study. Circ J 2010; 74:2365-71.

187. Chong ZZ, Kang JQ, Maiese K. Essential cellular regulatory elements of oxidative stress in early and late phases of apoptosis in the central nervous system. Antioxid Redox Signal 2004; 6:277-87.

188. Chong ZZ, Li F, Maiese K. The pro-survival pathways of $\mathrm{mTOR}$ and protein kinase B target glycogen synthase kinase-3beta and nuclear factorkappaB to foster endogenous microglial cell protection. Int J Mol Med 2007; 19:263-72.

189. Kang JQ, Chong ZZ, Maiese K. Critical role for Akt1 in the modulation of apoptotic phosphatidylserine exposure and microglial activation. Mol Pharmacol 2003; 64:557-69.

190. Karunakaran S, Diwakar L, Saeed U, Agarwal V, Ramakrishnan S, Iyengar $S$, et al. Activation of apoptosis signal regulating kinase 1 (ASK1) and translocation of death-associated protein, Daxx, in substantia nigra pars compacta in a mouse model of Parkinson's disease: protection by alpha-lipoic acid. Faseb J 2007; 21:2226-36.

191. Verdaguer E, Susana Gde A, Clemens A, Pallas M, Camins A. Implication of the transcription factor E2F-1 in the modulation of neuronal apoptosis. Biomed Pharmacother 2007; 61:390-9.

192. An WL, Cowburn RF, Li L, Braak H, Alafuzoff I, Iqbal $\mathrm{K}$, et al. Upregulation of phosphorylated/activated p70 S6 kinase and its relationship to neurofibrillary pathology in Alzheimer's disease. Am J Pathol 2003; 163:591-607.

193. Griffin RJ, Moloney A, Kelliher M, Johnston JA, Ravid R, Dockery P, et al. Activation of Akt/PKB, increased phosphorylation of Akt substrates and loss and altered distribution of Akt and PTEN are features of Alzheimer's disease pathology. J Neurochem 2005; 93:105-17.

194. Li X, Alafuzoff I, Soininen H, Winblad B, Pei JJ. Levels of mTOR and its downstream targets 4E-BP1, eEF2 and eEF2 kinase in relationships with tau in Alzheimer's disease brain. The FEBS journal 2005; 272:4211-20.

195. Paccalin M, Pain-Barc S, Pluchon C, Paul C, Besson MN, Carret-Rebillat AS, et al. Activated mTOR and PKR kinases in lymphocytes correlate with memory and cognitive decline in Alzheimer's disease. Dement Geriatr Cogn Disord 2006; 22:320-6.

196. Lafay-Chebassier C, Paccalin M, Page G, Barc-Pain S, Perault-Pochat MC, Gil R, et al. mTOR/p70S6k signalling alteration by Abeta exposure as well as in APPPS1 transgenic models and in patients with Alzheimer's disease. J Neurochem 2005; 94:215-25.

197. Ma T, Hoeffer CA, Capetillo-Zarate E, Yu F, Wong H, Lin MT, et al. Dysregulation of the mTOR pathway mediates impairment of synaptic plasticity in a mouse model of Alzheimer's disease. PLoS One 2010; 5.

198. Spilman P, Podlutskaya N, Hart MJ, Debnath J, Gorostiza O, Bredesen D, et al. Inhibition of mTOR by rapamycin abolishes cognitive deficits and reduces amyloid-beta levels in a mouse model of Alzheimer's disease. PLoS One 2010; 5:9979. 
199. Chano T, Saji M, Inoue H, Minami K, Kobayashi T, Hino O, et al. Neuromuscular abundance of RB1CC1 contributes to the non-proliferating enlarged cell phenotype through both RB1 maintenance and TSC1 degradation. Int J Mol Med 2006; 18:425-32.

200. Watanabe R, Chano T, Inoue H, Isono T, Koiwai O, Okabe H. Rblccl is critical for myoblast differentiation through Rb1 regulation. Virchows Arch 2005; 447:643-8.

201. Chano T, Okabe H, Hulette CM. RB1CC1 insufficiency causes neuronal atrophy through mTOR signaling alteration and involved in the pathology of Alzheimer's diseases. Brain Res 2007; 1168:97-105.

202. Li F, Chong ZZ, Maiese K. Cell Life Versus Cell Longevity: The Mysteries Surrounding the NAD(+) Precursor Nicotinamide. Curr Med Chem 2006; 13:883-95.

203. Corradetti MN, Inoki K, Guan KL. The stress-inducted proteins RTP801 and RTP801L are negative regulators of the mammalian target of rapamycin pathway. J Biol Chem 2005; 280:9769-72.

204. Lin L, Qian Y, Shi X, Chen Y. Induction of a cell stress response gene RTP801 by DNA damaging agent methyl methanesulfonate through CCAAT/enhancer binding protein. Biochemistry 2005; 44:3909-14.

205. Malagelada C, Ryu EJ, Biswas SC, Jackson-Lewis V, Greene LA. RTP801 is elevated in Parkinson brain substantia nigral neurons and mediates death in cellular models of Parkinson's disease by a mechanism involving mammalian target of rapamycin inactivation. J Neurosci 2006; 26:9996-10005.

206. Malagelada C, Jin ZH, Greene LA. RTP801 is induced in Parkinson's disease and mediates neuron death by inhibiting Akt phosphorylation/activation. J Neurosci 2008; 28:14363-71.

207. Santini E, Heiman M, Greengard P, Valjent E, Fisone G. Inhibition of mTOR signaling in Parkinson's disease prevents L-DOPA-induced dyskinesia. Science signaling 2009; $2: 36$

208. Chong ZZ, Maiese K. Targeting WNT, protein kinase $\mathrm{B}$ and mitochondrial membrane integrity to foster cellular survival in the nervous system. Histol Histopathol 2004; 19:495-504

209. Maiese K, Chong ZZ. Insights into oxidative stress and potential novel therapeutic targets for Alzheimer disease. Restor Neurol Neurosci 2004; 22:87-104.

210. Choi KC, Kim SH, Ha JY, Kim ST, Son JH. A novel mTOR activating protein protects dopamine neurons against oxidative stress by repressing autophagy related cell death. J Neurochem 2010; 112:366-76.

211. Aronin N, Chase K, Young C, Sapp E, Schwarz C, Matta N, et al. CAG expansion affects the expression of mutant Huntingtin in the Huntington's disease brain. Neuron 1995; 15:1193-201.

212. Norremolle A, Riess O, Epplen JT, Fenger K, Hasholt $\mathrm{L}$, Sorensen SA. Trinucleotide repeat elongation in the Huntingtin gene in Huntington disease patients from 71 Danish families. Hum Mol Genet 1993; 2:1475-6.

213. Kim J, Klionsky DJ. Autophagy, cytoplasm-to-vacuole targeting pathway and pexophagy in yeast and mammalian cells. Annu Rev Biochem 2000; 69:303-42.

214. Gorka M, Daniewski WM, Gajkowska B, Lusakowska E, Godlewski MM, Motyl T. Autophagy is the dominant type of programmed cell death in breast cancer MCF-7 cells exposed to AGS 115 and EFDAC, new sesquiterpene analogs of paclitaxel. Anti-cancer drugs 2005; 16:777-88.

215. Hara T, Nakamura K, Matsui M, Yamamoto A, Nakahara Y, Suzuki-Migishima R, et al. Suppression of basal autophagy in neural cells causes neurodegenerative disease in mice. Nature 2006; 441:885-9.

216. Hsu KF, Wu CL, Huang SC, Wu CM, Hsiao JR, Yo YT, et al. Cathepsin L mediates resveratrol-induced autophagy and apoptotic cell death in cervical cancer cells. Autophagy 2009; 5:451-60.

217. Mujumdar N, Saluja AK. Autophagy in pancreatic cancer: An emerging mechanism of cell death. Autophagy 2010; 6:997-8.
218. Ponpuak M, Delgado MA, Elmaoued RA, Deretic V. Monitoring autophagy during Mycobacterium tuberculosis infection. Methods Enzymol 2009; 452:345-61.

219. Simone C. Signal-dependent control of autophagy and cell death in colorectal cancer cell: the role of the p38 pathway. Autophagy 2007; 3:468-71.

220. Sarkar S, Ravikumar B, Rubinsztein DC. Autophagic clearance of aggregate-prone proteins associated with neurodegeneration. Methods Enzymol 2009; 453:83-110.

221. Blommaart EF, Luiken JJ, Blommaart PJ, van Woerkom GM, Meijer AJ. Phosphorylation of ribosomal protein S6 is inhibitory for autophagy in isolated rat hepatocytes. J Biol Chem 1995; 270:2320-6.

222. Jung $\mathrm{CH}$, Ro $\mathrm{SH}$, Cao J, Otto NM, Kim DH. mTOR regulation of autophagy. FEBS Lett 2010; 584:1287-95.

223. Berger Z, Ravikumar B, Menzies FM, Oroz LG Underwood BR, Pangalos MN, et al. Rapamycin alleviates toxicity of different aggregate-prone proteins. Hum Mol Genet 2006; 15:433-42.

224. Ravikumar B, Vacher C, Berger Z, Davies JE, Luo S, Oroz LG, et al. Inhibition of mTOR induces autophagy and reduces toxicity of polyglutamine expansions in fly and mouse models of Huntington disease. Nat Genet 2004; 36:585-95.

225. Floto RA, Sarkar S, Perlstein EO, Kampmann B, Schreiber SL, Rubinsztein DC. Small molecule enhancers of rapamycin-induced TOR inhibition promote autophagy, reduce toxicity in Huntington's disease models and enhance killing of mycobacteria by macrophages. Autophagy 2007; 3:620-2

226. Ravikumar B, Stewart A, Kita H, Kato K, Duden R, Rubinsztein DC. Raised intracellular glucose concentrations reduce aggregation and cell death caused by mutant huntingtin exon 1 by decreasing mTOR phosphorylation and inducing autophagy. Hum Mol Genet 2003; 12:985-94.

227. Yuan W, Stromhaug PE, Dunn WA Jr. Glucoseinduced autophagy of peroxisomes in Pichia pastoris requires a unique E1-like protein. Mol Biol Cell 1999; 10:1353-66.

228. Curatolo P, Bombardieri R, Jozwiak S. Tuberous sclerosis. Lancet 2008; 372:657-68

229. Meikle L, Pollizzi K, Egnor A, Kramvis I, Lane H, Sahin M, et al. Response of a neuronal model of tuberous sclerosis to mammalian target of rapamycin (mTOR) inhibitors: effects on mTORC1 and Ak signaling lead to improved survival and function. J Neurosci 2008; 28:5422-32.

230. Jozwiak J, Kotulska K, Lojek M, Galus R, Jozwiak $S$, Polnik D, et al. Fibroblasts from normal skin of a tuberous sclerosis patient show upregulation of mTOR pathway. The American Journal of dermatopathology 2009; 31:68-70.

231. Hofbauer GF, Marcollo-Pini A, Corsenca A, Kistler $\mathrm{AD}$, French LE, Wuthrich RP, et al. The mTOR inhibitor rapamycin significantly improves facial angiofibroma lesions in a patient with tuberous sclerosis. The British journal of dermatology 2008; 159:473-5

232. Pollizzi K, Malinowska-Kolodziej I, Stumm M, Lane $\mathrm{H}$, Kwiatkowski D. Equivalent benefit of mTORC1 blockade and combined PI3K-mTOR blockade in a mouse model of tuberous sclerosis. Mol Cancer 2009; $8: 38$.

233. Di Nardo A, Kramvis I, Cho N, Sadowski A, Meikle L, Kwiatkowski DJ, et al. Tuberous sclerosis complex activity is required to control neuronal stress responses in an mTOR-dependent manner. J Neurosci 2009; 29:5926-37.

234. Dasgupta B, Yi Y, Hegedus B, Weber JD, Gutmann DH. Cerebrospinal fluid proteomic analysis reveals dysregulation of methionine aminopeptidase- 2 expression in human and mouse neurofibromatosis 1-associated glioma. Cancer Res 2005; 65:9843-50.

235. Hegedus B, Banerjee D, Yeh TH, Rothermich S, Perry A, Rubin JB, et al. Preclinical cancer therapy in a mouse model of neurofibromatosis-1 optic glioma. Cancer Res 2008 ; 68:1520-8.
236. Johannessen CM, Johnson BW, Williams SM, Chan AW, Reczek EE, Lynch RC, et al. TORC1 is essentia for NF1-associated malignancies. Curr Biol 2008; 18:56-62.

237. Brown V, Jin P, Ceman S, Darnell JC, O’Donnell WT, Tenenbaum SA, et al. Microarray identification of FMRP-associated brain mRNAs and altered mRNA translational profiles in fragile X syndrome. Cell 2001; 107:477-87.

238. Ceman S, O’Donnell WT, Reed M, Patton S, Pohl J, Warren ST. Phosphorylation influences the translation state of FMRP-associated polyribosomes. Hum Mol Genet 2003; 12:3295-305.

239. Narayanan U, Nalavadi V, Nakamoto M, Pallas DC Ceman S, Bassell GJ, et al. FMRP phosphorylation reveals an immediate-early signaling pathway triggered by group I mGluR and mediated by PP2A. J Neurosci 2007; 27:14349-57.

240. Narayanan U, Nalavadi V, Nakamoto M, Thomas G, Ceman S, Bassell GJ, et al. S6K1 phosphorylates and regulates fragile $\mathrm{X}$ mental retardation protein (FMRP) with the neuronal protein synthesis-dependent mammalian target of rapamycin (mTOR) signaling cascade. J Biol Chem 2008; 283:18478-82.

241. Chen S, Atkins CM, Liu CL, Alonso OF, Dietrich WD, Hu BR. Alterations in mammalian target of rapamycin signaling pathways after traumatic brain injury. J Cereb Blood Flow Metab 2007; 27:939-49.

242. Erlich S, Alexandrovich A, Shohami E, PinkasKramarski R. Rapamycin is a neuroprotective treatment for traumatic brain injury. Neurobiol Dis 2007; 26:86-93.

243. Hu LY, Sun ZG, Wen YM, Cheng GZ, Wang SL, Zhao $\mathrm{HB}$, et al. ATP-mediated protein kinase B Akt/mammalian target of rapamycin mTOR/p70 ribosomal S6 protein $\mathrm{p} 70 \mathrm{~S} 6$ kinase signaling pathway activation promotes improvement of locomotor function after spinal cord injury in rats. Neuroscience 2010; 169:1046-62.

244. Holmes GL, Stafstrom CE. Tuberous sclerosis complex and epilepsy: recent developments and future challenges. Epilepsia 2007; 48:617-30.

245. Waltereit R, Welzl H, Dichgans J, Lipp HP, Schmid WJ, Weller M. Enhanced episodic-like memory and kindling epilepsy in a rat model of tuberous sclerosis. J Neurochem 2006; 96:407-13.

246. Zeng LH, Xu L, Gutmann DH, Wong M. Rapamycin prevents epilepsy in a mouse model of tuberous sclerosis complex. Ann Neurol 2008; 63:444-53.

247. Zeng LH, Rensing NR, Wong M. The mammalian target of rapamycin signaling pathway mediates epileptogenesis in a model of temporal lobe epilepsy. J Neurosci 2009; 29:6964-72.

248. Buckmaster PS, Ingram EA, Wen X. Inhibition of the mammalian target of rapamycin signaling pathway suppresses dentate granule cell axon sprouting in a rodent model of temporal lobe epilepsy. J Neurosci 2009; 29:8259-69.

249. Huang X, Zhang H, Yang J, Wu J, McMahon J, Lin $\mathrm{Y}$, et al. Pharmacological inhibition of the mammalian target of rapamycin pathway suppresses acquired epilepsy. Neurobiol Dis 2010; 40:193-9.

250. Maiese K, Chong ZZ, Shang YC, Hou J. Rogue proliferation versus restorative protection: where do we draw the line for Wnt and forkhead signaling? Expert opinion on therapeutic targets 2008; 12:905-16.

251. Maiese K, Vincent A, Lin SH, Shaw T. Group I and Group III metabotropic glutamate receptor subtype provide enhanced neuroprotection. J Neurosci Res 2000; 62:257-72

252. Mari C, Karabiyikoglu M, Goris ML, Tait JF, Yenari MA, Blankenberg FG. Detection of focal hypoxicischemic injury and neuronal stress in a rodent model of unilateral MCA occlusion/reperfusion using radiolabeled annexin V. Eur J Nucl Med Mol Imaging 2004; 31:733-9. 
253. Chong ZZ, Kang J, Li F, Maiese K. mGluRI Targets Microglial Activation and Selectively Prevents Neuronal Cell Engulfment Through Akt and Caspase Dependent Pathways. Curr Neurovasc Res 2005; 2:197-211.

254. Bailey TJ, Fossum SL, Fimbel SM, Montgomery JE, Hyde DR. The inhibitor of phagocytosis, O-phosphoL-serine, suppresses Muller glia proliferation and cone cell regeneration in the light-damaged zebrafish retina. Exp Eye Res 2010; 91:601-12.

255. Chong ZZ, Kang JQ, Maiese K. Metabotropic glutamate receptors promote neuronal and vascular plasticity through novel intracellular pathways. Histol Histopathol 2003; 18:173-89.

256. Mallat M, Marin-Teva JL, Cheret C. Phagocytosis in the developing CNS: more than clearing the corpses. Curr Opin Neurobiol 2005; 15:101-7.

257. Li F, Chong ZZ, Maiese K. Winding through the WNT pathway during cellular development and demise. Histol Histopathol 2006; 21:103-24.

258. Chong ZZ, Kang JQ, Maiese K. Erythropoietin fosters both intrinsic and extrinsic neuronal protection through modulation of microglia, Akt $1, \mathrm{Bad}$ and caspase-mediated pathways. Br J Pharmacol 2003; 138:1107-18.

259. Maiese K, Ahmad I, TenBroeke M, Gallant J. Metabotropic glutamate receptor subtypes independently modulate neuronal intracellular calcium. J Neurosci Res 1999; 55:472-85.

260. Vincent AM, Maiese K. Direct temporal analysis of apoptosis induction in living adherent neurons. J Histochem Cytochem 1999; 47:661-72.

261. Chong ZZ, Lin SH, Kang JQ, Maiese K. Erythropoietin prevents early and late neuronal demise through modulation of Akt1 and induction of caspase 1, 3 and 8. J Neurosci Res 2003; 71:659-69.

262. Chong ZZ, Lin SH, Kang JQ, Maiese K. The tyrosine phosphatase SHP2 modulates MAP kinase p38 and caspase 1 and 3 to foster neuronal survival. Cell $\mathrm{Mol}$ Neurobiol 2003; 23:561-78.

263. Maiese K, Boccone L. Neuroprotection by peptide growth factors against anoxia and nitric oxide toxicity requires modulation of protein kinase C. J Cereb Blood Flow Metab 1995; 15:440-9.

264. Maiese K, Boniece IR, Skurat K, Wagner JA. Protein kinases modulate the sensitivity of hippocampal neurons to nitric oxide toxicity and anoxia. J Neurosci Res 1993; 36:77-87.

265. Maiese K, TenBroeke M, Kue I. Neuroprotection of lubeluzole is mediated through the signal transduction pathways of nitric oxide. J Neurochem 1997; 68:710-4.

266. Salinas M, Diaz R, Abraham NG, Ruiz de Galarreta CM, Cuadrado A. Nerve growth factor protects against 6-hydroxydopamine-induced oxidative stress by increasing expression of heme oxygenase- 1 in a phosphatidylinositol-3-kinase-dependent manner. J Biol Chem 2003; 278:13898-904.

267. Leytin V, Allen DJ, Mykhaylov S, Lyubimov E, Freedman J. Thrombin-triggered platelet apoptosis. J Thromb Haemost 2006; 4:2656-63.

268. Maiese K, Vincent AM. Critical temporal modulation of neuronal programmed cell injury. Cell $\mathrm{Mol}$ Neurobiol 2000; 20:383-400.

269. Maiese K, Vincent AM. Membrane asymmetry and DNA degradation: functionally distinct determinants of neuronal programmed cell death. J Neurosci Res 2000; 59:568-80.

270. Dombroski D, Balasubramanian K, Schroit AJ. Phosphatidylserine expression on cell surfaces promotes antibody- dependent aggregation and thrombosis in beta2-glycoprotein I-immune mice. J Autoimmun 2000; 14:221-9

271. Jessel R, Haertel S, Socaciu C, Tykhonova S, Diehl HA. Kinetics of apoptotic markers in exogeneously induced apoptosis of EL4 cells. J Cell Mol Med 2002; 6:82-92.

272. Chong ZZ, Maiese K. The Src homology 2 domain tyrosine phosphatases SHP-1 and SHP-2: diversified control of cell growth, inflammation and injury. Histol Histopathol 2007; 22:1251-67.
273. Vincent AM, Maiese K. Nitric oxide induction of neuronal endonuclease activity in programmed cell death. Exp Cell Res 1999; 246:290-300.

274. Vincent AM, TenBroeke M, Maiese K. Metabotropic glutamate receptors prevent programmed cell death through the modulation of neuronal endonuclease activity and intracellular pH. Exp Neurol 1999; 155:79-94.

275. Chong ZZ, Shang YC, Hou J, Maiese K. Wnt1 neuroprotection translates into improved neurological function during oxidant stress and cerebral ischemia through AKT1 and mitochondrial apoptotic pathways. Oxid Med Cell Longev 2010; 3:153-65.

276. Hatip-Al-Khatib I, Iwasaki K, Chung EH, Egashira N, Mishima K, Fujiwara M. Inhibition of poly (ADPribose) polymerase and caspase-3, but not caspase-1, prevents apoptosis and improves spatial memory of rats with twice-repeated cerebral ischemia. Life Sci 2004 75:1967-78.

277. Rizk NN, Rafols J, Dunbar JC. Cerebral ischemi induced apoptosis and necrosis in normal and diabetic rats. Brain Res 2005; 1053:1-9.

278. Chong ZZ, Kang JQ, Maiese K. Apaf-1, Bcl- $x_{L}$, Cytochrome $c$, and Caspase-9 Form the Critica Elements for Cerebral Vascular Protection by Erythropoietin. J Cereb Blood Flow Metab 2003; 23:320-30.

279. Aguirre D, Boya P, Bellet D, Faivre S, Troalen F, Benard J, et al. Bcl-2 and CCND1/CDK4 expression levels predict the cellular effects of mTOR inhibitors in human ovarian carcinoma. Apoptosis 2004; 9:797-805.

280. Altomare DA, Wang HQ, Skele KL, De Rienzo A, Klein-Szanto AJ, Godwin AK, et al. AKT and mTOR phosphorylation is frequently detected in ovarian cancer and can be targeted to disrupt ovarian tumor cell growth. Oncogene 2004; 23:5853-7.

281. Asnaghi L, Calastretti A, Bevilacqua A, D’Agnano I, Gatti G, Canti G, et al. Bcl-2 phosphorylation and apoptosis activated by damaged microtubules require mTOR and are regulated by Akt. Oncogene 2004; 23:5781-91.

282. Beuvink I, Boulay A, Fumagalli S, Zilbermann F, Ruetz S, O'Reilly T, et al. The mTOR inhibitor RAD001 sensitizes tumor cells to DNA-damaged induced apoptosis through inhibition of p21 translation. Cell 2005; 120:747-59.

283. Bu X, Le C, Jia F, Guo X, Zhang L, Zhang B, et al. Synergistic effect of mTOR inhibitor rapamycin and fluorouracil in inducing apoptosis and cell senescence in hepatocarcinoma cells. Cancer biology \& therapy 2008; 7:392-6.

284. Deeb D, Gao X, Dulchavsky SA, Gautam SC. CDDOme induces apoptosis and inhibits Akt, mTOR and NFkappaB signaling proteins in prostate cancer cells. Anticancer Res 2007; 27:3035-44.

285. Deeb D, Gao X, Dulchavsky SA, Gautam SC. CDDOMe inhibits proliferation, induces apoptosis, down regulates Akt, mTOR, NFkappaB and NFkappaBregulated antiapoptotic and proangiogenic proteins in TRAMP prostate cancer cells. Journal of experimental therapeutics \& oncology 2008; 7:31-9.

286. Foster DA. Phosphatidic acid signaling to $m$ TOR signals for the survival of human cancer cells. Biochim Biophys Acta 2009; 1791:949-55

287. Hansel DE, Platt E, Orloff M, Harwalker J, Seth $S$, Hicks JL, et al. Mammalian target of rapamycin (mTOR) regulates cellular proliferation and tumor growth in urothelial carcinoma. Am J Pathol 2010; 176:3062-72.

288. Ji J, Zheng PS. Activation of mTOR signaling pathway contributes to survival of cervical cancer cells. Gynecol Oncol 2010; 117:103-8.

289. Mungamuri SK, Yang X, Thor AD, Somasundaram K. Survival signaling by Notch1: mammalian target of rapamycin (mTOR)-dependent inhibition of p53. Cancer Res 2006; 66:4715-24.
290. Noske A, Lindenberg JL, Darb-Esfahani S, Weicher W, Buckendahl AC, Roske A, et al. Activation of mTOR in a subgroup of ovarian carcinomas: correlation with p-eIF-4E and prognosis. Oncology reports 2008; 20:1409-17.

291. Seeliger H, Guba M, Kleespies A, Jauch KW, Bruns CJ Role of mTOR in solid tumor systems: a therapeutical target against primary tumor growth, metastases and angiogenesis. Cancer Metastasis Rev 2007; 26:611-21.

292. Villanueva A, Chiang DY, Newell P, Peix J, Thung $\mathrm{S}$, Alsinet C, et al. Pivotal role of mTOR signaling in hepatocellular carcinoma. Gastroenterology 2008; 135:1972-83.

293. Zhang YJ, Dai Q, Sun DF, Xiong H, Tian XQ, Gao $\mathrm{FH}$, et al. mTOR signaling pathway is a target for the treatment of colorectal cancer. Ann Surg Oncol 2009; 16:2617-28.

294. Miriuka SG, Rao V, Peterson M, Tumiati L, Delgado $\mathrm{DH}$, Mohan R, et al. mTOR inhibition induces endothelial progenitor cell death. Am J Transplant 2006; 6:2069-79

295. Dormond O, Madsen JC, Briscoe DM. The effects of mTOR-Akt interactions on anti-apoptotic signaling in vascular endothelial cells. J Biol Chem 2007; 282:23679-86

296. Brachmann SM, Hofmann I, Schnell C, Fritsch C Wee $\mathrm{S}$, Lane $\mathrm{H}$, et al. Specific apoptosis induction by the dual PI3K/mTor inhibitor NVP-BEZ235 in HER2 amplified and PIK3CA mutant breast cancer cells. Proc Natl Acad Sci USA 2009; 106:22299-304.

297. deGraffenried LA, Friedrichs WE, Russell DH, Donzis EJ, Middleton AK, Silva JM, et al. Inhibition of mTOR activity restores tamoxifen response in breast cancer cells with aberrant Akt Activity. Clin Cancer Res 2004; 10:8059-67.

298. Faried LS, Faried A, Kanuma T, Nakazato T, Tamura T, Kuwano $\mathrm{H}$, et al. Inhibition of the mammalian target of rapamycin (mTOR) by rapamycin increases chemosensitivity of CaSki cells to paclitaxel. Eur J Cancer 2006; 42:934-47.

299. Nagata Y, Takahashi A, Ohnishi K, Ota I, Ohnishi T, Tojo T, et al. Effect of rapamycin, an mTOR inhibitor, on radiation sensitivity of lung cancer cells having different p53 gene status. Int J Oncol 2010; 37:1001-10.

300. Ory B, Moriceau G, Redini F, Heymann D. mTOR inhibitors (rapamycin and its derivatives) and nitrogen containing bisphosphonates: bi-functional compounds for the treatment of bone tumours. Curr Med Chem 2007; 14:1381-7

301. Amato RJ, Jac J, Giessinger S, Saxena S, Willis JP. A phase 2 study with a daily regimen of the oral mTOR inhibitor RAD001 (everolimus) in patients with metastatic clear cell renal cell cancer. Cancer 2009; 115:2438-46

302. Chan S, Scheulen ME, Johnston S, Mross K, Cardoso F, Dittrich C, et al. Phase II study of temsirolimus (CCI-779), a novel inhibitor of mTOR, in heavily pretreated patients with locally advanced or metastatic breast cancer. J Clin Oncol 2005; 23:5314-22.

303. Raymond E, Alexandre J, Faivre S, Vera K, Materman E, Boni J, et al. Safety and pharmacokinetics of escalated doses of weekly intravenous infusion of CCI-779, a novel mTOR inhibitor, in patients with cancer. J Clin Oncol 2004; 22:2336-47.

304. Rizell M, Andersson M, Cahlin C, Hafstrom L, Olausson M, Lindner P. Effects of the mTOR inhibitor sirolimus in patients with hepatocellular and cholangiocellular cancer. International journal of clinical oncology/Japan Society of Clinical Oncology 2008; 13:66-70.

305. Wolpin BM, Hezel AF, Abrams T, Blaszkowsky LS, Meyerhardt JA, Chan JA, et al. Oral mTOR inhibitor everolimus in patients with gemcitabine-refractory metastatic pancreatic cancer. J Clin Oncol 2009; 27:193-8. 
306. Chen L, Xu B, Liu L, Luo Y, Yin J, Zhou H, et al. Hydrogen peroxide inhibits mTOR signaling by activation of AMPKalpha leading to apoptosis of neuronal cells. Lab Invest 2010; 90:762-73.

307. Wu X, Reiter CE, Antonetti DA, Kimball SR, Jefferson LS, Gardner TW. Insulin promotes rat retinal neuronal cell survival in a p70S6K-dependent manner. J Biol Chem 2004; 279:9167-75.

308. Chen L, Liu L, Luo Y, Huang S. MAPK and mTOR pathways are involved in cadmium-induced neuronal apoptosis. J Neurochem 2008; 105:251-61.

309. Hou G, Xue L, Lu Z, Fan T, Tian F, Xue Y. An activated $\mathrm{mTOR} / \mathrm{p} 70 \mathrm{~S} 6 \mathrm{~K}$ signaling pathway in esophageal squamous cell carcinoma cell lines and inhibition of the pathway by rapamycin and siRNA against mTOR Cancer Lett 2007; 253:236-48.
310. Kojima K, Shimanuki M, Shikami M, Samudio IJ, Ruvolo V, Corn P, et al. The dual PI3 kinase/mTOR inhibitor PI-103 prevents $\mathrm{p} 53$ induction by $\mathrm{Mdm} 2$ inhibition but enhances $\mathrm{p} 53$-mediated mitochondrial apoptosis in p53 wild-type AML. Leukemia 2008; 22:1728-36.

311. Yau CY, Wheeler JJ, Sutton KL, Hedley DW. Inhibition of integrin-linked kinase by a selective smal molecule inhibitor, QLT0254, inhibits the PI3K/ $\mathrm{PKB} / \mathrm{mTOR}$, Stat 3 and FKHR pathways and tumor growth and enhances gemcitabine-induced apoptosis in human orthotopic primary pancreatic cancer xenografts. Cancer Res 2005; 65:1497-504.
312. Pastor MD, Garcia-Yebenes I, Fradejas N, Perez-Ortiz JM, Mora-Lee S, Tranque P, et al. mTOR/S6 kinase pathway contributes to astrocyte survival during ischemia. J Biol Chem 2009; 284:22067-78.

313. Koh PO. Melatonin prevents ischemic brain injury through activation of the mTOR/p70S6 kinase signaling pathway. Neurosci Lett 2008; 444:74-8.

314. Koh PO, Cho JH, Won CK, Lee HJ, Sung JH, Kim MO. Estradiol attenuates the focal cerebral ischemic injury through mTOR/p70S6 kinase signaling pathway. Neurosci Lett 2008; 436:62-6. 


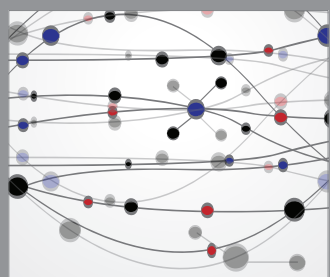

The Scientific World Journal
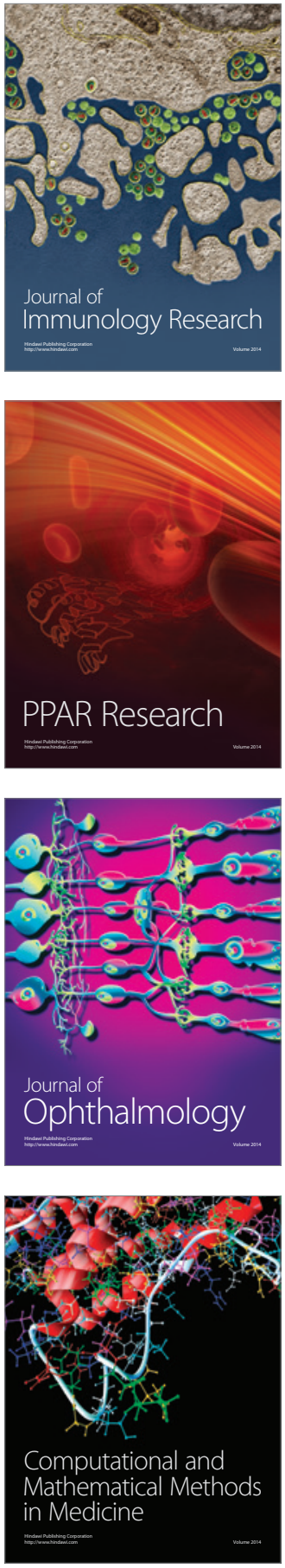

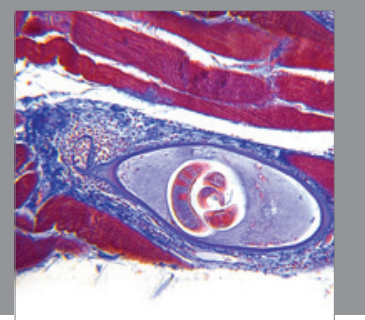

Gastroenterology

Research and Practice
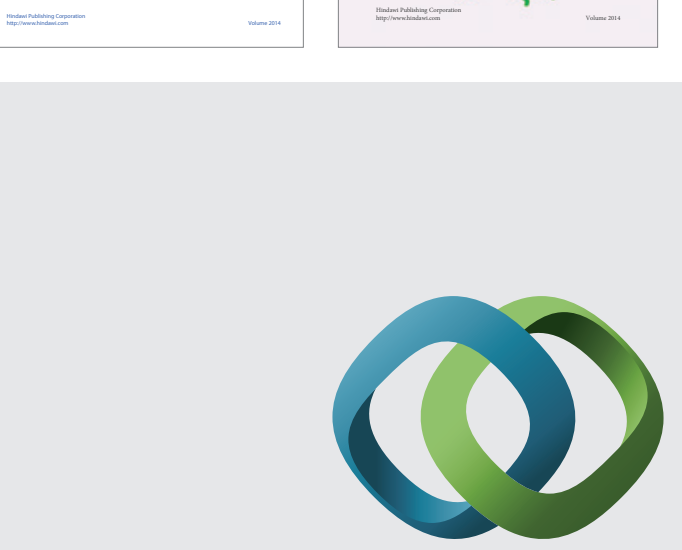

\section{Hindawi}

Submit your manuscripts at

http://www.hindawi.com
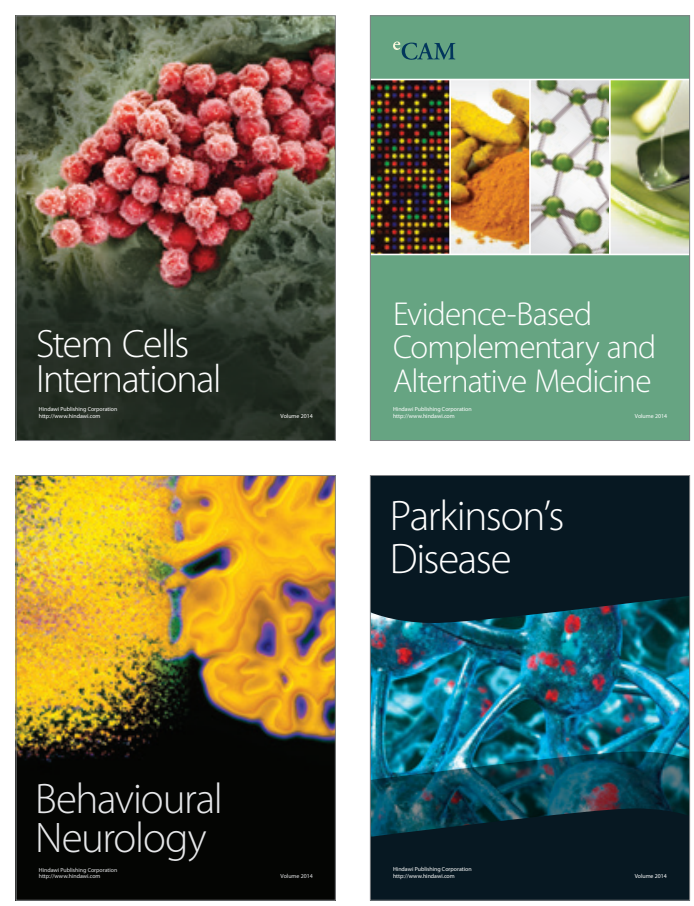

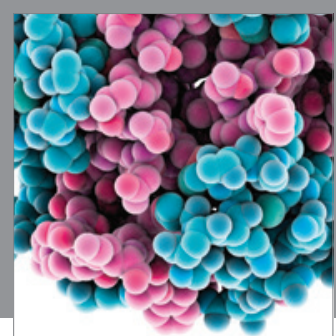

Journal of
Diabetes Research

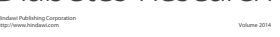

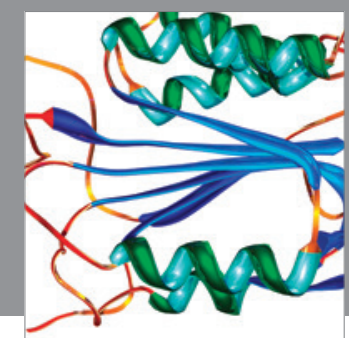

Disease Markers
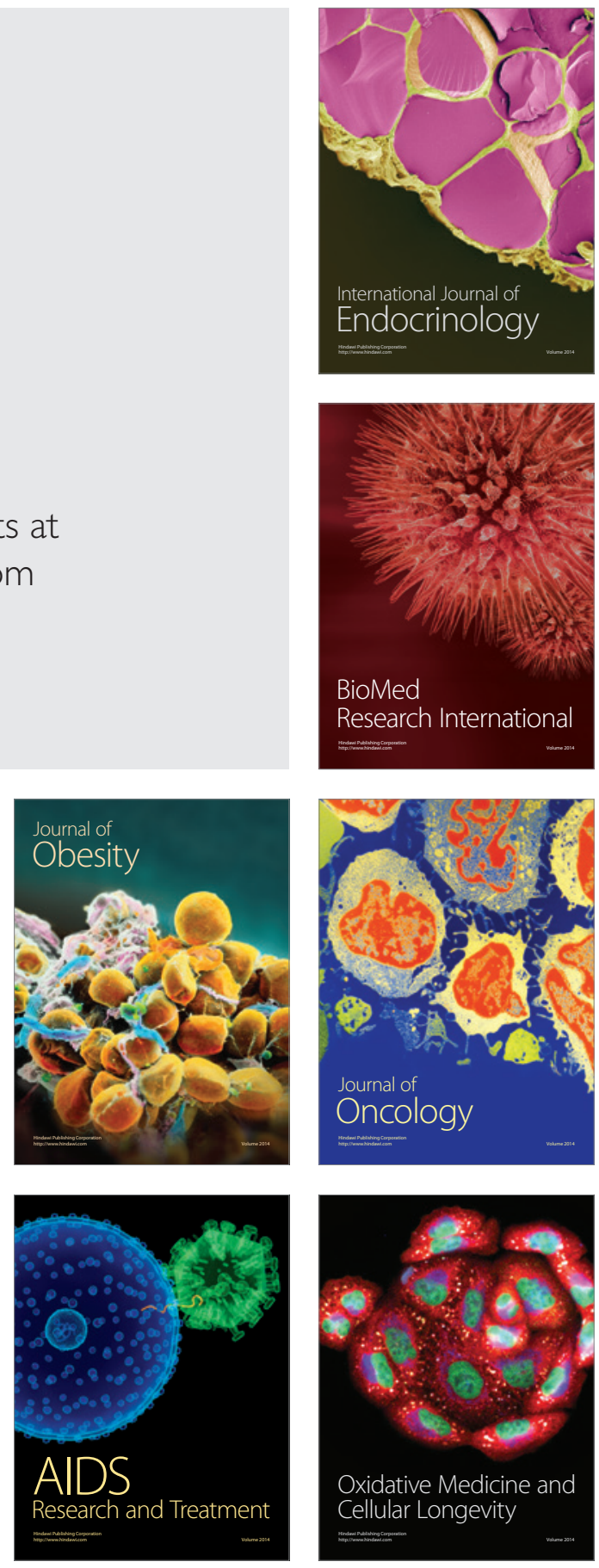